\title{
Apoptosis and necroptosis of mouse hippocampal and parenchymal astrocytes, microglia and neurons caused by Angiostrongylus cantonensis infection
}

Zhang Mengying ${ }^{1,2,3}$, Xu Yiyue $^{1,2}$, Pan Tong ${ }^{1,2}$, Hu Yue ${ }^{1,2,3}$, Yanin Limpanont ${ }^{4}$, Huang Ping ${ }^{1,2,3}$, Kamolnetr Okanurak ${ }^{4}$, Wu Yanqi ${ }^{1,2,3}$, Paron Dekumyoy ${ }^{4}$, Zhou Hongli ${ }^{1,2,3}$, Dorn Watthanakulpanich ${ }^{4}$, Wu Zhongdao ${ }^{1,2,3}$, Wang Zhi $5^{*}$ and Lv Zhiyue ${ }^{1,2,3^{*}}$

\begin{abstract}
Background: Angiostrongylus cantonensis has been the only parasite among Angiostrongylidae to cause human central nervous system infection characterized by eosinophilic meningitis or meningoencephalitis. The mechanism of the extensive neurological impairments of hosts caused by $A$. cantonensis larvae remains unclear. The aim of the present study was to investigate apoptosis, necroptosis and autophagy in the brains of mice infected with $A$. cantonensis, which will be valuable for better understanding the pathogenesis of angiostrongyliasis cantonensis.

Methods: Functional and histological neurological impairments of brain tissues from mice infected with $A$. cantonensis were measured by the Morris water maze test and haematoxylin and eosin (H\&E) staining, respectively. The transcriptional and translational levels of apoptosis-, necroptosis- and autophagy-related genes were quantified by quantitative real-time polymerase chain reaction (RT-PCR), and assessed by western blot and immunohistochemistry (IHC) analysis. Apoptotic and necroptotic cells and their distributions in infected brain tissues were analysed by flow cytometry and transmission electron microscopy (TEM).

Results: Inflammatory response in the central nervous system deteriorated as A. cantonensis infection evolved, as characterized by abundant inflammatory cell infiltration underneath the meninges, which peaked at 21 days postinfection (dpi). The learning and memory capacities of the mice were significantly decreased at $14 \mathrm{dpi}$, indicating prominent impairment of their cognitive functions. Compared with those of the control group, the mRNA levels of caspase-3, -4, -6, and RIP3 and the protein levels of caspase-4, cleaved caspase-3, cleaved caspase-6, RIP3, and pRIP3 were obviously elevated. However, no changes in the mRNA or protein levels of FADD, Beclin-1 or LC3B were evident, indicating that apoptosis and necroptosis, but not autophagy, occurred in the brain tissues of mice infected with A. cantonensis. The quantitative RT-PCR, western blot, IHC, flow cytometry and TEM results further revealed the apoptotic and necroptotic microglia, astrocytes and neurons in the parenchymal and hippocampal regions of infected mice.

(Continued on next page)
\end{abstract}

\footnotetext{
* Correspondence: wangzhispider@hotmail.com; Ivzhiyue@mail.sysu.edu.cn

${ }^{5}$ College of Bioscience \& Biotechnology, Hunan Agriculture University,

Changsha 410128, China

${ }^{1}$ Fifth Affiliated Hospital, Zhongshan School of Medicine, Sun Yat-sen

University, Guangzhou 510080, China

Full list of author information is available at the end of the article
} 
(Continued from previous page)

Conclusions: To our knowledge, we showed for the first time that A. cantonensis infection causes the apoptosis and necroptosis of microglia and astrocytes in the parenchymal and hippocampal regions of host brain tissues, further demonstrating the pathogenesis of A. cantonensis infection and providing potential therapeutic targets for the management of angiostrongyliasis.

Keywords: Angiostrongylus cantonensis, Pathogenesis, Apoptosis, Necroptosis

\section{Background}

Angiostrongylus cantonensis is the most common cause of eosinophilic meningitis worldwide. As accidental hosts, humans can become infected via the ingestion of undercooked intermediate hosts (Pomacea canaliculata, Achatina fulica, etc.) or contaminated water or food that contains third-stage larvae (L3) [1, 2]. After penetrating the intestinal wall, $A$. cantonensis migrate in the body through the bloodstream, finally passing the blood-brain barrier to further develop in the central nervous system (CNS). Larvae in the brain tissue cause direct mechanical damage and severe inflammation, resulting in eosinophilic meningitis or encephalitis. In addition to the cerebrum and meninges, the cerebellum, brainstem and spinal cord can be affected. Clinical symptoms, manifested as CNS injuries, include severe headache, neck stiffness, convulsions and nausea [3].

Parasitic infections of the CNS include protozoans (Plasmodium, Trypanosoma cruzi, Toxoplasma gondii and amoebae) and metazoans (Schistosoma, Paragonimus, larval stages of Taenia solium, Echinococcus granulosus, Spirometra mansoni, and A. cantonensis), and the pathogenesis of these neuroparasites include the apoptosis and necroptosis of host cells [4]. The major pathogenetic mechanism of cerebral amebiasis lies in the killing of mammalian cells by trophozoite-induced apoptosis [5]. Disruption of the endothelium via apoptosis leads to the leakage of red blood cells, ring haemorrhage, and activated coagulation in adjacent nervous tissue in cerebral malaria [6]. In neurocysticercosis, neurological deficits, particularly learning and memory deficits, are generated by the extensive and significant apoptosis of hippocampal cells [7] and apoptosis of CD3+ T lymphocytes in the brains of hosts induced by $T$. solium cysticerci may be a mechanism by which the parasite downregulates its host's cellular immune response during early cysticercosis [8]. The most common presentation of cerebral toxoplasmosis in HIV-infected patients is mass lesions consisting of well-defined areas of coagulative necroptosis with or without haemorrhage [9]. The gross appearance of tumoural lesions in neuroschistosomiasis is characterized by the presence of necroticexudative granuloma containing eggs surrounded by necrotic and elongated epithelioid cells [10].
Although A. cantonensis is the most common cause of eosinophilic meningitis worldwide, the major cell populations and cell injuries in the host brain after infection are not entirely clear [3]. To further reveal the pathogenesis of angiostrongyliasis cantonensis in this study, the Morris water maze test was used to test the neural functionality of $A$. cantonensis-infected hosts. Quantitative RT-PCR, western blot and immunohistochemistry (IHC) analyses were combined to detect apoptosis, necroptosis and autophagy in mouse cerebral parenchymal and hippocampal cells. Flow cytometry and transmission electron microscopy (TEM) were performed to evaluate the cell death of parenchymal and hippocampal astrocytes, neurons and microglia.

\section{Methods \\ Animals}

Female BALB/c mice (6-8 weeks old) were purchased from Guangdong Medical Laboratory Animal Center and housed in a specific pathogen-free environment and had unlimited access to food and water.

One batch of mice was randomly divided into 6 groups (9 mice per group) and orally infected with A. cantonensis third-stage larvae (L3, 30 per mouse), except for the normal controls. Groups were named according to the number of day(s) post-infection (dpi): group G1 (uninfected mice), group G2 (mice infected for 1 day), group G3 (mice infected for 3 days), group G4 (mice infected for 7 days), group G5 (mice infected for 14 days) and group G6 (mice infected for 21 days). Brain samples from each group were prepared for mRNA and protein extraction or fixed for immunohistochemistry analysis. Animals were euthanized under deep anaesthesia by ether inhalation followed by blood-letting.

Another batch of mice was used for studying neurological function, flow cytometry analysis and transmission electron microscopic observation. They were divided into 4 groups and orally infected with 30 L3 for 7,14 and 21 days or not infected (control group). After neurological function evaluation, flow cytometry analysis of brain tissues was carried out. Brain tissues from the 0 dpi and 21 dpi groups were subjected to transmission electron microscopy. 
Infecting BALB/c mice with $A$. cantonensis larvae

All the infectious $A$. cantonensis L3 used in this study were obtained from Biomphalaria glabrata 21 days after infection of the first-stage larvae (L1) of the parasite. The snails were homogenized and digested in a pepsin$\mathrm{HCl}$ solution ( $\mathrm{pH} 2.0,500 \mathrm{IU}$ pepsin/g tissue) at $37{ }^{\circ} \mathrm{C}$ in an incubator for $40 \mathrm{~min}$. Then, infectious L3 were washed in PBS and counted under an anatomical microscope for animal infection [11].

\section{Neurological function evaluation}

The Morris water maze test was used as described in a previous study [12] to compare learning and memory skills between normal and infected mice. The water maze consisted of a large, circular tank $(180 \mathrm{~cm}$ in diameter $\times 60 \mathrm{~cm}$ high) filled with water $\left(22 \pm 1{ }^{\circ} \mathrm{C}\right)$. A stationary platform was hidden $1.5 \mathrm{~cm}$ below the water surface, and white paint was added to make the platform invisible. During cued training, mice were placed into the pool four times each training day (days 1, 2 and 3), once from each of the four quadrants, and then required to find the platform. Animals that located the platform were allowed to rest for $30 \mathrm{~s}$; those that failed to find the platform within $60 \mathrm{~s}$ were gently guided to the platform to rest for $30 \mathrm{~s}$. Escape latency, or the time required to reach to the platform, was recorded for each mouse (day 4 ), and place navigation was used to evaluate their learning and memory skills. The spatial probe test, used to evaluate mouse memory retention, was performed on day 5. The platform was removed, and the probe task was performed in the third quadrant. The swim escape latency, average swim speed, time spent in the target quadrant, and number of times the mice crossed the previous location of the platform were recorded by a video tracking system (Taimeng Tech, Chengdu, China).

\section{Haematoxylin and eosin (H\&E) staining}

Mice brains were collected at $0,1,3,7,14$ and $21 \mathrm{dpi}$, fixed in $4 \%$ paraformaldehyde and embedded in paraffin. Brain sections were then de-paraffinized in xylene, rehydrated via graded alcohols and stained with H\&E (Biosharp, Wuhan, China) according to the manufacturer's protocol. Pathological changes were observed under an inverted microscope (Leica, Heidelberg, Germany).

\section{Sample extraction and cDNA synthesis}

Total mouse brain RNA was extracted using TRIzol $^{\circledR}$ Reagent (Thermo Fisher Scientific, Waltham, USA) according to the manufacturer's protocol, and RNA yield and purity were determined by the NanoDropTM spectrophotometer (Thermo Fisher Scientific). The first cDNA strand was synthesized at $42{ }^{\circ} \mathrm{C}$ for $1 \mathrm{~h}$ using the RevertAid First Strand cDNA Synthesis Kit (Thermo Fisher Scientific).

Quantitative real-time polymerase chain reaction (RT-PCR) For RT-PCR, primers for detecting cell death genes were designed using AlleleID software. The sequences of the target genes and that of the internal control $\beta$-actin gene are listed in Table 1. RT-PCR was performed with SYBR ${ }^{\circ}$ Premix Ex Taq ${ }^{\mathrm{Tm}}$ (TaKaRa, Dalian, China) in a volume of $20 \mu \mathrm{l}$. PCR samples were preheated to $95{ }^{\circ} \mathrm{C}$ for $30 \mathrm{~s}$, followed by 40 cycles of $95{ }^{\circ} \mathrm{C}$ for $5 \mathrm{~s}$ and $60{ }^{\circ} \mathrm{C}$ for $20 \mathrm{~s}$. The melt curve was then created by heating at $95{ }^{\circ} \mathrm{C}$ for $1 \mathrm{~s}, 65{ }^{\circ} \mathrm{C}$ for $15 \mathrm{~s}$, and $55^{\circ} \mathrm{C}$ for $30 \mathrm{~s}$. Reactions were

Table 1 The primers used for quantitative real-time PCR

\begin{tabular}{|c|c|c|}
\hline Gene symbol & Forward primer sequence & Reverse primer sequence \\
\hline Caspase-2 & GCACAGGAAATGCAAGAGAA & CTTGGAGCTGAAGCAGTTG \\
\hline Caspase-3 & AGCAGCTTTGTGTGTGTGATTCTAA & AGTTTCGGCTTTCCAGTCAGAC \\
\hline Caspase-4 & TGTCATCTCTTTGATATATTCCTGAAG & CAAGGTTGCCCGATCAAT \\
\hline Caspase-6 & AGACAAGCTGGACAACGTGACC & CCAGGAGCCATTCACAGTTTCT \\
\hline Caspase-9 & TCCTGGTACATCGAGACCTTG & AAGTCCCTITCGCAGAAACAG \\
\hline Cytochrome c & AGGCTGCTGGATTCTCTTACAC & CAGGGATGTACTIIITGGGATT \\
\hline Smac & AAGAGCTGCACCAGAAAGCA & TCTGACTGTCAATGGCAGGA \\
\hline $\mathrm{BCl}-2$ & GTGGATGACTGAGTACCTGAACC & AGCCAGGAGAAATCAAACAGAG \\
\hline Beclin-1 & TGATCCAGGAGCTGGAAGAT & CAAGCGACCCAGTCTGAAAT \\
\hline Bad & CAGCCACCAACAGTCATC & СТССТССАТСССТТСАТСС \\
\hline $\mathrm{BCl}-\mathrm{XI}$ & CTITCGGGATGGAGTAAAC & AGGTGGTCATTCAGATAGG \\
\hline RIP3 & AAGTGCAGATTGGGAACTACAACTC & AGAATGTTGTGAGCTTCAGGAAGTG \\
\hline FADD & AAGGTGTCTGGTGGGTGTTC & GCATCAGCAAGAGCAGTAGG \\
\hline LC3B & CCCCACCAAGATCCCAGT & CGCTCATGTTCACGTGGT \\
\hline$\beta$-actin & GCTGTCCCTGTATGCCTCT & GTCTTTACGGATGTCAACG \\
\hline
\end{tabular}




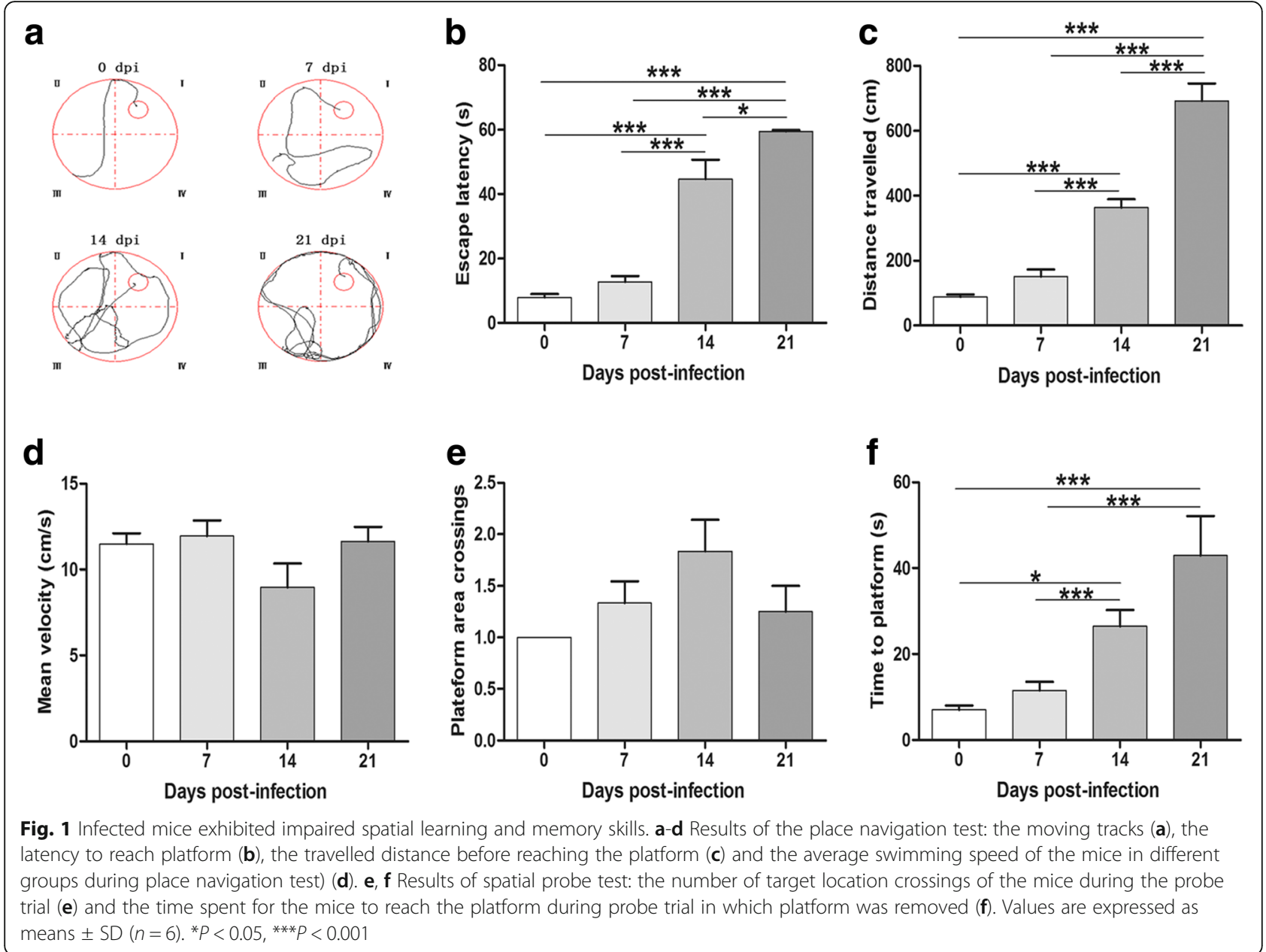

performed on the LightCycler $480^{\circ}$ Real-Time PCR System (Roche Diagnostics, Reinach, Switzerland), and experiments were repeated three times as independent biological replicates. The mRNA levels of these genes were measured by the Ct value (threshold cycle), and the relative expression levels were calculated with the $2^{-\Delta \Delta C t}$ method [13].

\section{Western blot}

Total mouse brain proteins were extracted using Western-IP Lysis Buffer (Beyotime,Wuhan, China) and quantified using the BCA protein assay kit (Beyotime, Wuhan, China). In total, $10 \mu \mathrm{g}$ of total proteins were electrophoresed on $12 \%$ SDS polyacrylamide gels and transferred onto nitrocellulose membranes. The membranes

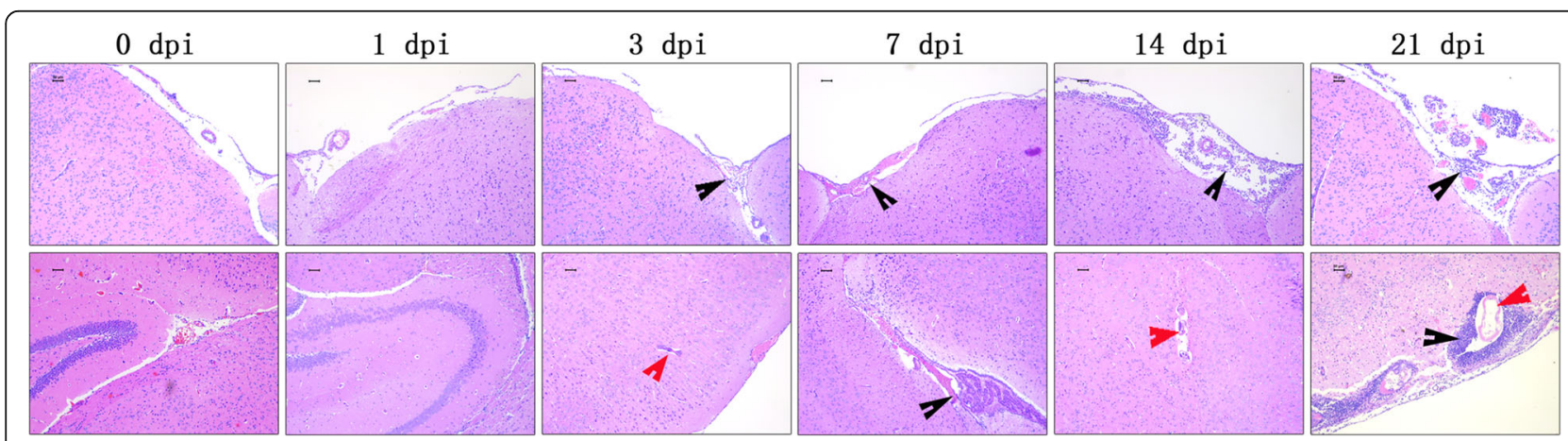

Fig. 2 Histopathological injuries of mice infected with A. cantonensis. The black arrows show that inflammatory cells infiltrated into the brain of the infected mouse, and aggregated on the meninges and caused thickening of the meninges. The red arrows indicate the worms in the parenchyma of brains of the infected mice. (100x magnification). Scale-bars: $50 \mu \mathrm{m}$ 
were blocked with $\mathrm{PBS} /$ Tween $20^{\circ}$ (PBST) containing $5 \%$ non-fat milk for $90 \mathrm{~min}$ at room temperature and then incubated overnight at $4{ }^{\circ} \mathrm{C}$ with the following primary antibodies: anti-caspase-3, anti-cleaved caspase-3, anti-caspase-6, anti-cleaved caspase-6, anti-RIP3, antiBeclin-1 (Cell Signaling Technology, Danvers, USA), anti-caspase-4, anti-phosphor-RIP3 (Abcam, Cambridge, UK), anti-LC3B (Beyotime,Wuhan, China), and anti- $\beta$-actin (Cell Signaling Technology, Danvers, USA) as the control. After incubation with HRP-conjugated goat anti-rabbit IgG or HRP-conjugated goat anti-rat IgG (Cell Signaling Technology), the nitrocellulose membranes were washed three times, and bands were visualized by chemiluminescence with Pierce Enhanced
Chemiluminescence Detection Reagent (Millipore, Burlington, USA) on the ChemiDoc ${ }^{\text {Tax }}$ Touch imaging system (Bio-Rad, Hercules, USA). Relative band intensity was analysed by AlphaViewTM software (Alpha Innotech Corporation, San Jose, USA).

\section{Immunohistochemistry (IHC)}

Mouse brains were isolated, fixed in $4 \%$ paraformaldehyde (PFA) overnight at $4{ }^{\circ} \mathrm{C}$ and embedded in paraffin. Then, the brain sections were de-paraffinized in xylene, rehydrated via a graded ethanol series, and subjected to antigen retrieval by boiling the slices in citrate buffer ( $\mathrm{pH}$ 6.0) with high heat for $15 \mathrm{~min}$ and medium heat for $15 \mathrm{~min}$ in a microwave oven. For

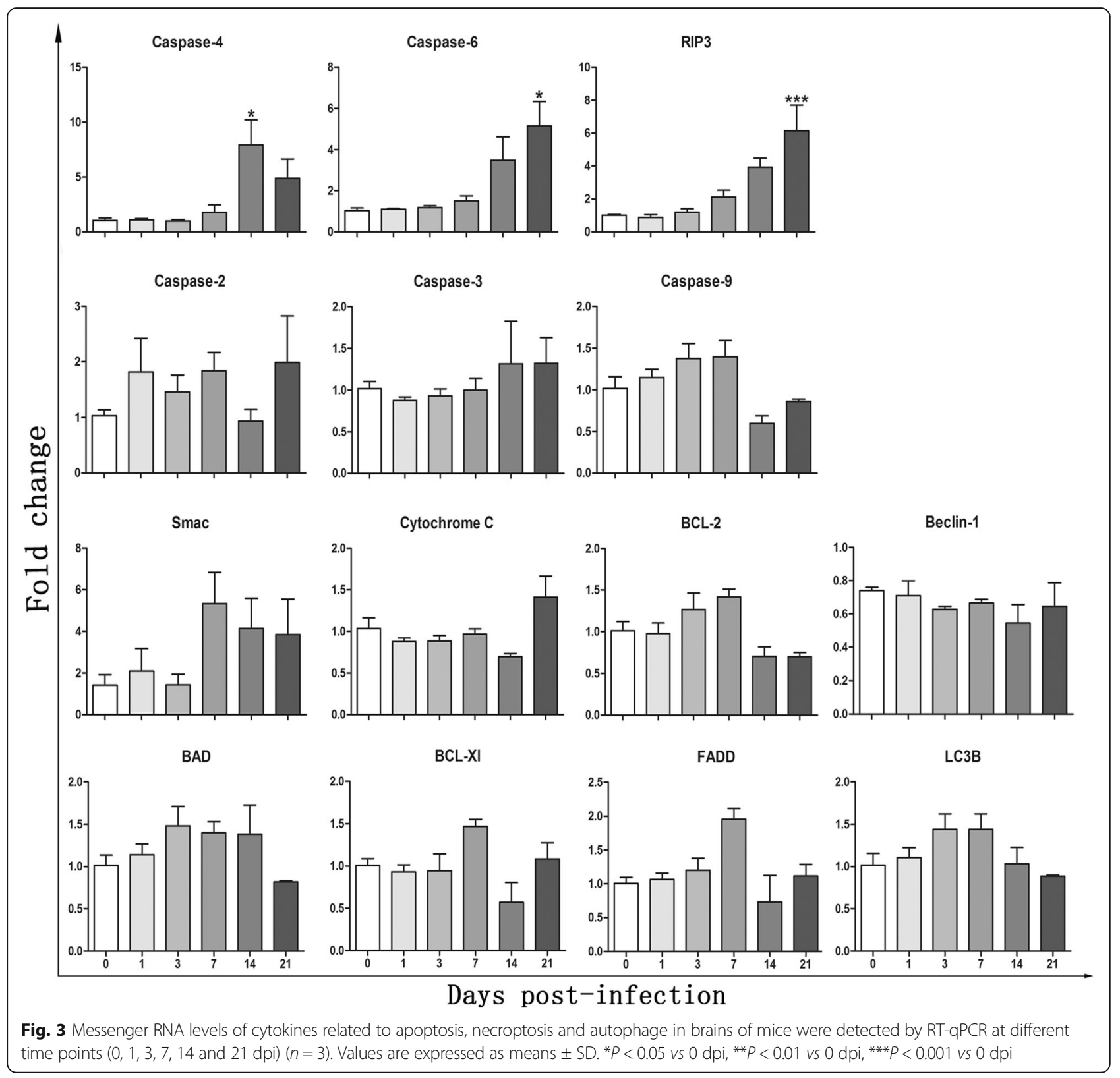




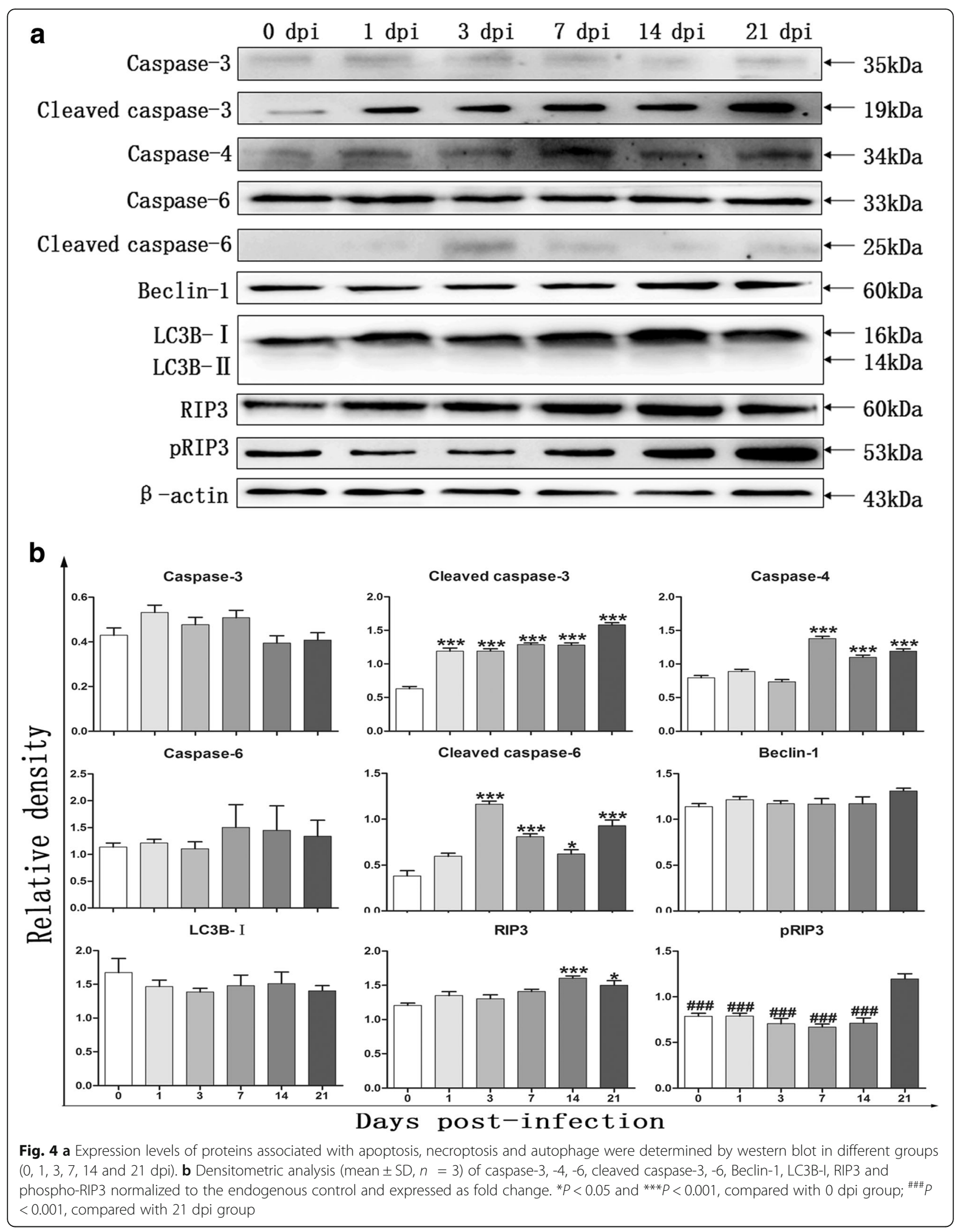


IHC analysis, sections were treated with $3 \% \mathrm{H}_{2} \mathrm{O}_{2}$ for $10 \mathrm{~min}$ to remove endogenous peroxidase, blocked with $1 \%$ bovine serum albumin (BSA) in PBS (blocking solution) at room temperature for $1 \mathrm{~h}$, and incubated with anti-caspase-3, anti-cleaved caspase-3, anticaspase-6 (Cell Signaling Technology), anti-NeuN (Abcam) anti-RIP3 (ABclonal, Wuhan, China), or anti-LC3B (Beyotime) diluted in blocking solution at $4{ }^{\circ} \mathrm{C}$ overnight. After being washed 3 times in PBS, the sections were incubated with an HRP-conjugated secondary antibody (DAKO, Glostrup, Denmark) at room temperature for $30 \mathrm{~min}$ and then stained with 3, 3'-diaminobenzidine (DAB) for $15 \mathrm{~s}$. Haematoxylin was used for cell nuclei detection. Stained sections were visualized and digitally scanned with an inverted light microscope (Leica).

\section{Flow cytometry}

Mice were euthanized, and their parenchymal and hippocampal tissues were separated, removed and collected into $5 \mathrm{ml}$ of Dounce buffer (Hank's balanced salt solution containing $15 \mathrm{mM}$ HEPES and $0.5 \mathrm{mM} \mathrm{L-}$ glutamine). The samples were homogenized on ice using a glass homogenizer, and the suspensions were pipetted onto a $70 \mu \mathrm{m}$ cell strainer over a $15 \mathrm{ml}$ conical tube and then centrifuged for $1 \mathrm{~min}$ at $1000 \times \mathrm{rpm}$ at $4{ }^{\circ} \mathrm{C}$. The pellets were resuspended in FACS buffer $(0.5 \%$ BSA, $0.1 \% \mathrm{NaN}_{3}$ and $25 \mathrm{mM}$ HEPES in PBS) for single-cell suspension preparation. To increase the microglia yield, myelin was removed using Myelin Removal Beads II (Miltenyi Biotec, Bergisch Gladbach, Germany). Cells were blocked using Fc block prior to surface antibody staining at $4{ }^{\circ} \mathrm{C}$ for $30 \mathrm{~min}$ in the dark. In total, $2.5 \mu \mathrm{l}$ of

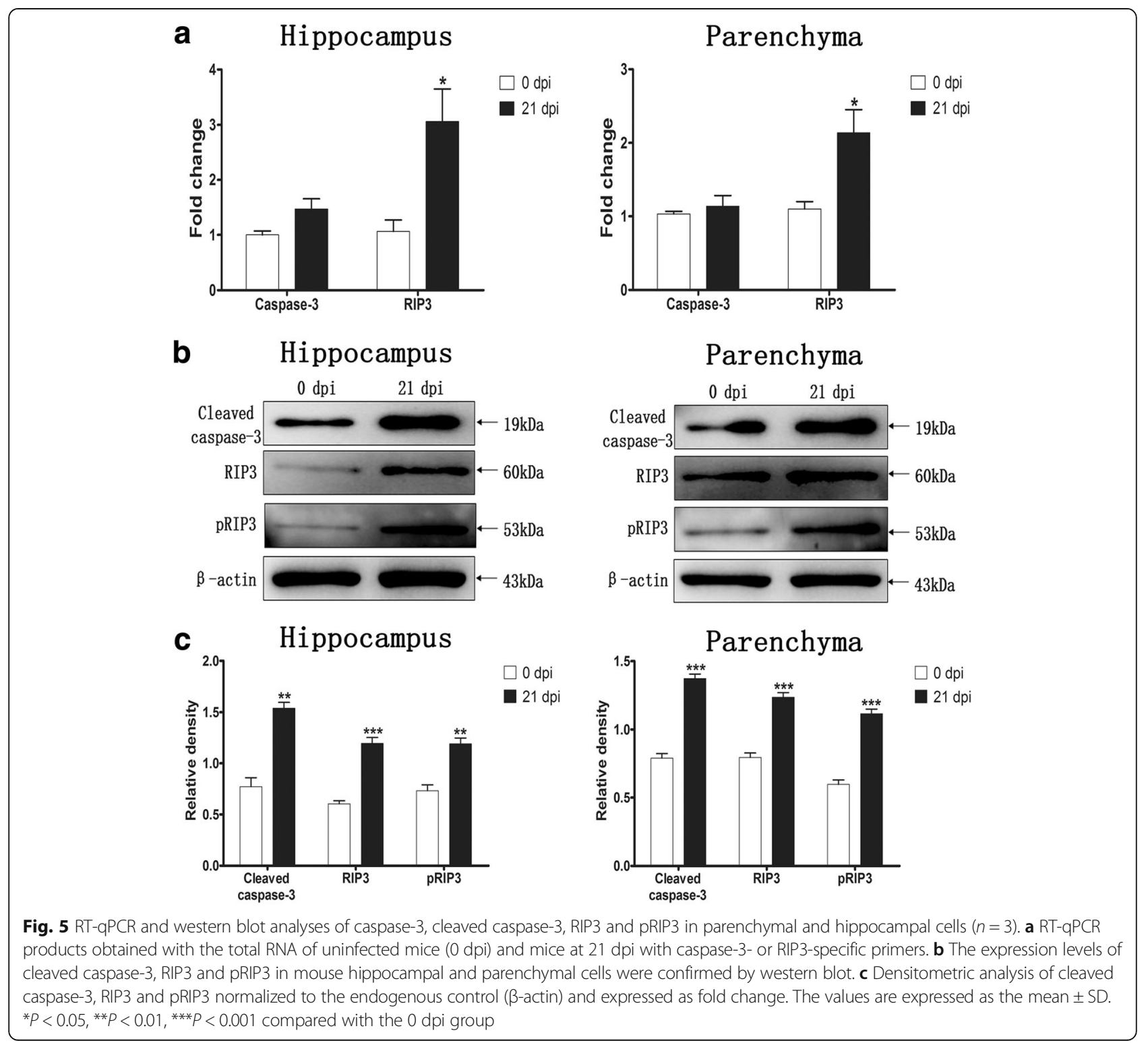


the following surface antibodies were used: Annexin V PE-Cyanine7, FVD eFluor 780 (eBioscience, Waltham, USA), CD45-BV421, and CD11b-BV711 (BD Biosciences, Franklin Lakes, USA). After a 20 min incubation, cell suspensions were fixed and permeabilized using fixation/permeabilization buffer (BD Biosciences) and intracellular antibodies $(0.5 \mu \mathrm{l}$ of NeuN-Alexa Fluor 488 and $2.5 \mu \mathrm{l}$ of PE-conjugated GFAP in $50 \mu \mathrm{l}$ of BD Perm/ WashTM buffer) were then added. Cells were analysed on a CytoFLEX S flow cytometer (Beckman Coulter, Atlanta, USA), and 10,000 cells were collected per tube. Data analysis was performed using FlowJo software (Tree Star, San Carlos, USA).

\section{Transmission electron microscopy (TEM)}

After perfusion with fixatives, small cubes of the lateroventral hippocampus and parenchymal layers were excised from the brains of normal and 21 dpi mice $(n=3$ per group) and immediately fixed in $2.5 \%$ glutaraldehyde $(v / v)$ in $100 \mathrm{mM}$ phosphate buffer with $2 \%$ PFA $(w / v)$ at $4{ }^{\circ} \mathrm{C}$ overnight. The cubes were post-fixed in $1 \%$ osmium tetroxide in $100 \mathrm{mM}$ phosphate buffer for $1.5 \mathrm{~h}$ at room temperature. The samples were then washed, dehydrated in a graded series of ethanol (50, 70, 80, 90 and 100\%), cleared in acetone and embedded in Eponate 12 resin (Ted Pella Inc., Redding, USA). Ultrathin sections (60 nm thickness) were cut with a diamond knife (Diatome, Nidau, Switzerland) on a Leica EM UC7 ultramicrotome, stained with a $2.0 \%$ uranyl acetate solution and a $2.0 \%$ lead citrate solution, and observed using a Tecnai G2 Spirit Twin electron microscope (FEI, Hillsboro, USA) operated at $80 \mathrm{kV}$.

\section{Statistical analyses}

Statistical analyses were performed using GraphPad Prism 5.0 (GraphPad Software, San Diego, USA) with two-tailed unpaired Student's t-test and SPSS 20.0 (IBM Corp., NY, USA) with one-way analysis of variance (ANOVA) followed by the Tukey-Kramer test. The data are presented as the means \pm standard deviation (SD). Differences among comparisons were considered statistically significant for $P$-values less than 0.05 .

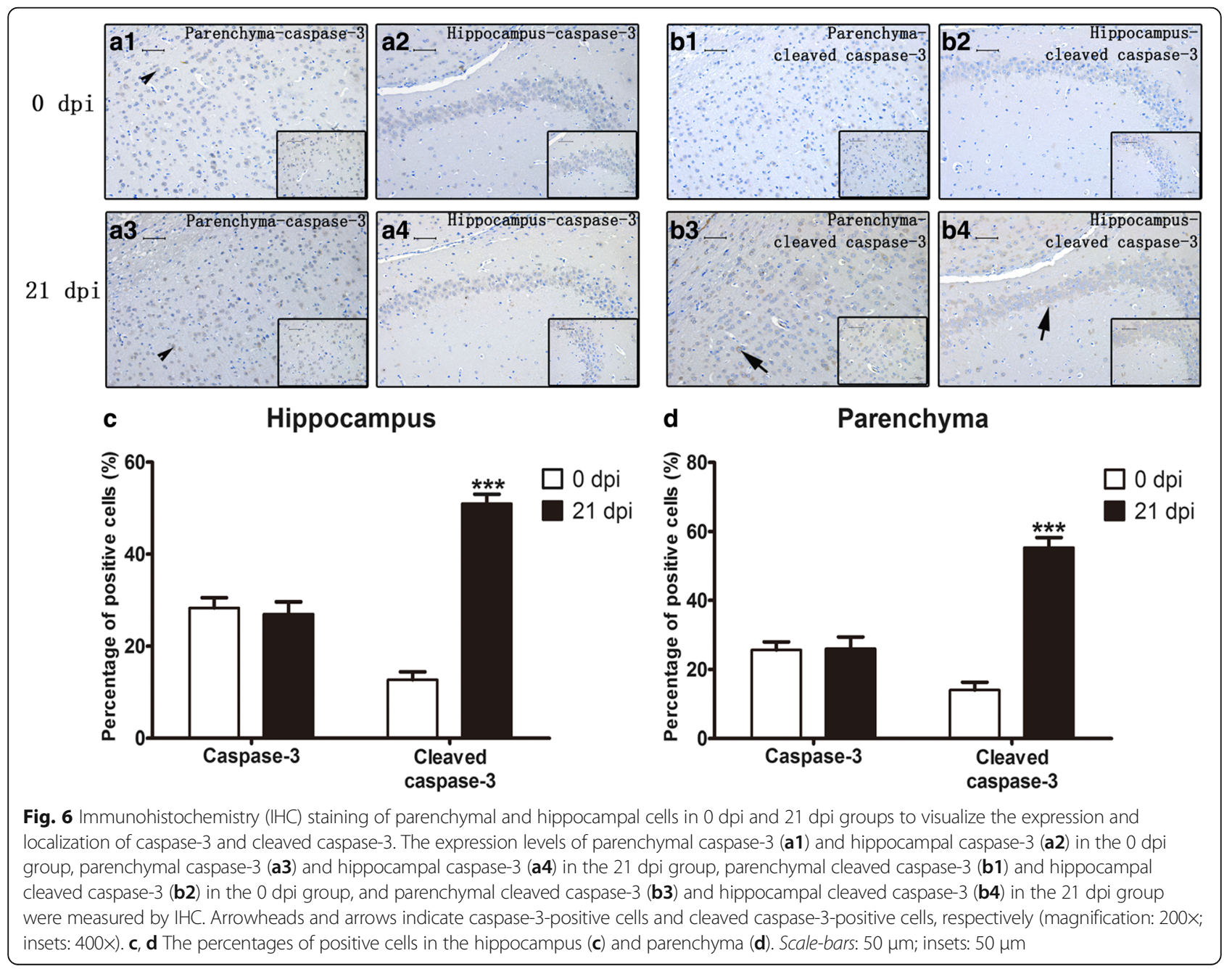




\section{Results}

\section{Morris water maze test}

During the 4 day place navigation test, significantly $\left(F_{(3,20)}=60.19, P<0.0001\right.$ and $F_{(3,20)}=73.31, P<0.0001$, respectively) prolonged escape latency times and extended swimming distances were observed in the $14 \mathrm{dpi}$ $(44.65 \pm 14.87 \mathrm{~s}$ and $362.89 \pm 63.82 \mathrm{~cm}$, respectively) and $21 \mathrm{dpi}(59.5 \pm 1.04 \mathrm{~s}$ and $692.49 \pm 130.11 \mathrm{~cm}$, respectively) groups compared with mice in the $0 \mathrm{dpi}(7.93 \pm$ $2.51 \mathrm{~s}$ and $88.31 \pm 17.99 \mathrm{~cm}$, respectively) and $7 \mathrm{dpi}$ $(12.76 \pm 4.35 \mathrm{~s}$ and $150.86 \pm 50.48 \mathrm{~cm}$, respectively) groups. In addition, disparity in the above two parameters between the $14 \mathrm{dpi}$ and $21 \mathrm{dpi}$ groups was statistically significant $\left(F_{(3,20)}=60.19, P=0.019\right.$ and $F_{(3,20)}=$ 73.31, $P<0.0001$, respectively) (Fig. $1 \mathrm{a}-\mathrm{c}$ ), while no significant differences in average swimming speed were observed between normal and infected mice $(P>0.05)$ (Fig. 1d). In the spatial probe test on day 5, no significant distinction among the groups in terms of platform area crossing were observed $(P>0.05)$ (Fig. 1e).
However, mice in the $14 \mathrm{dpi}(26.47 \pm 9.37 \mathrm{~s})$ and $21 \mathrm{dpi}$ $(42.93 \pm 18.34 \mathrm{~s})$ post-infection groups significantly extended their time spent in the target quadrant compared with the 0 dpi $(6.97 \pm 2.48 \mathrm{~s})$ and $7 \mathrm{dpi}(11.48 \pm 5 \mathrm{~s})$ groups $\left(F_{(3,20)}=14.25, P<0.0001\right)$, while no significant difference in the time spent in the target quadrant between the $21 \mathrm{dpi}$ and $14 \mathrm{dpi}$ groups was observed $(P>0.05)$ (Fig. 1f). The results indicated a clear timedependent reduction in the learning and memory retention capacities of mice infected with $A$. cantonensis.

\section{Histopathological observation of the brains of mice infected with $A$. cantonensis}

$\mathrm{H} \& \mathrm{E}$ staining reflected the histopathological injuries and inflammation of mouse brains infected with $A$. cantonensis. No histopathological injuries or inflammatory cells were observed in the brains of the $0 \mathrm{dpi}$ and 1 dpi groups. After $3 \mathrm{dpi}$, a few inflammatory cells infiltrated into the mouse brains, aggregating on and thickening the meninges (black arrows). Worm

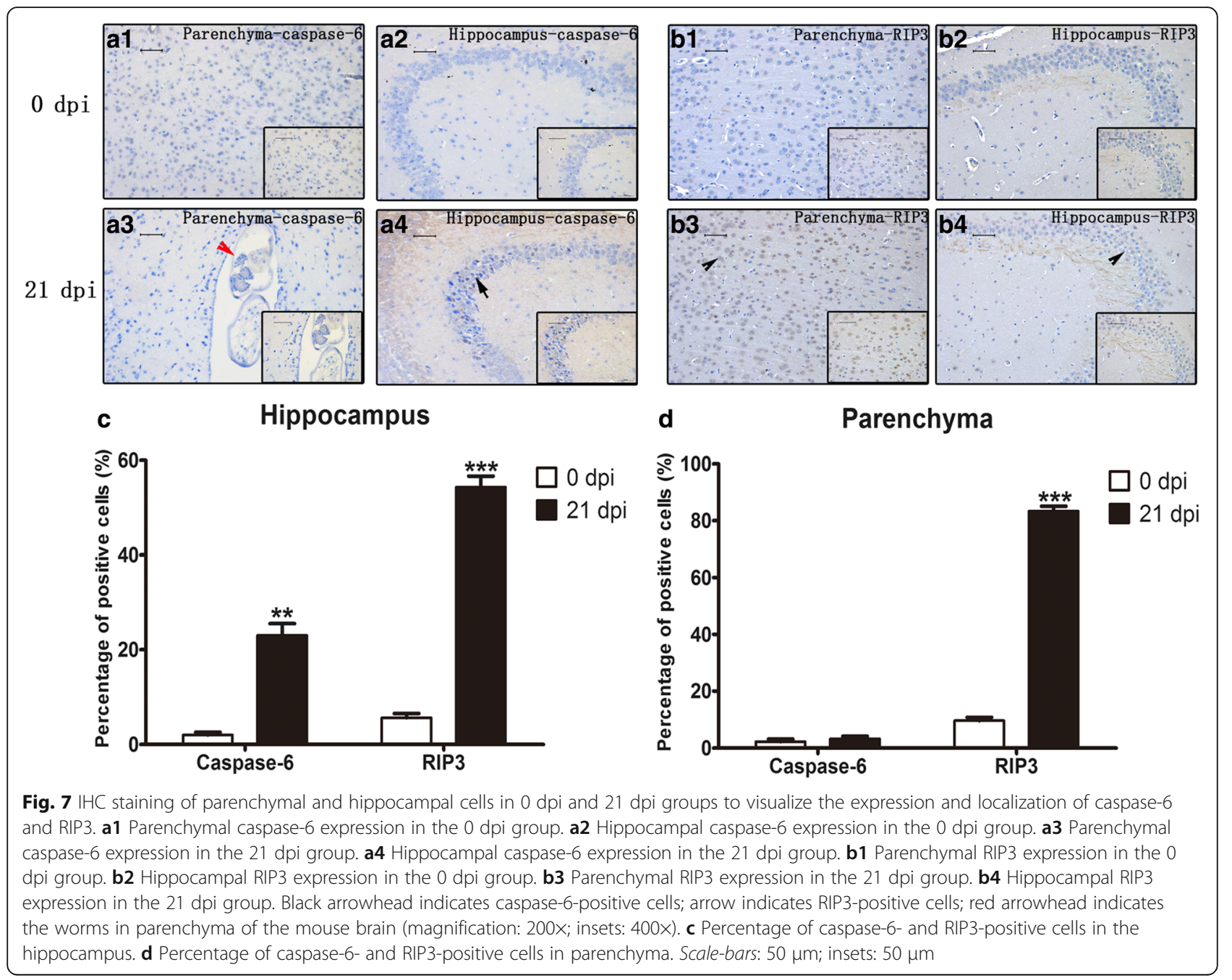


transection in the infected parenchyma illustrated that this parasite could move into the brain after only 3 days of infection (red arrows). As the infection time extended, more inflammatory cells infiltrated into the mouse brains, and their histopathological statuses became more serious (Fig. 2).

\section{Detection of mRNA levels by quantitative RT-PCR}

To detect brain injuries in the infected mice, the mRNA levels of some molecules related to apoptosis, necroptosis and autophagy, including caspase-2, -3, $-4,-6,-9$, Cc, Smac, Bcl-2, Bad, Bcl-Xl, RIP3, FADD, Beclin-1 and LC3B, were measured. The mRNA levels of caspase-4, -6 and RIP3 in the infected mouse brains were 7-, 5- and 6-fold higher than those of normal mice. The mRNA levels of caspase-4, -6 and RIP3 increased as brain inflammation progressed, and the caspase- 6 and RIP3 mRNA levels peaked and had statistical significance at $21 \mathrm{dpi}\left(F_{(5,12)}=6.232, P=\right.$ 0.0004 and $F_{(5,12)}=8.755, P<0.0001$, respectively).
The mRNA level of caspase-4 peaked at $14 \mathrm{dpi}$ $\left(F_{(5,12)}=6.386, P=0.0051\right)$ (Fig. 3).

\section{Determination of protein expression using western blot}

We next detected the expression levels of proteins associated with apoptosis, necroptosis and autophagy by western blot. Figure 4 shows obviously increased levels of the apoptotic proteins cleaved caspase-3 $\left(F_{(5,12)}=80.86, \quad P<0.0001\right)$, caspase $-4 \quad\left(F_{(5,12)}=56.65\right.$, $P<0.0001)$ and cleaved caspase- $6\left(F_{(5,12)}=35.58, P<\right.$ 0.0001 ) after $A$. cantonensis infection, and these levels peaked at $21 \mathrm{dpi}, 7 \mathrm{dpi}$ and $3 \mathrm{dpi}$, respectively. RIP3 expression was clearly upregulated from $14 \mathrm{dpi}$ $\left(F_{(5,12)}=8.458, P=0.0009\right)$ to $21 \mathrm{dpi}\left(F_{(5,12)}=8.458\right.$, $P=0.011)$ and peaked at $14 \mathrm{dpi}$. pRIPK3, an active mediator of necroptosis, was significantly elevated at 21 dpi $\left(F_{(5,12)}=17.17, \quad P<0.0001\right)$. However, there was no significant effect on the expression levels of total caspase- 3 , total caspase- 6 and Beclin- 1 proteins compared to those of normal mice, and no clear

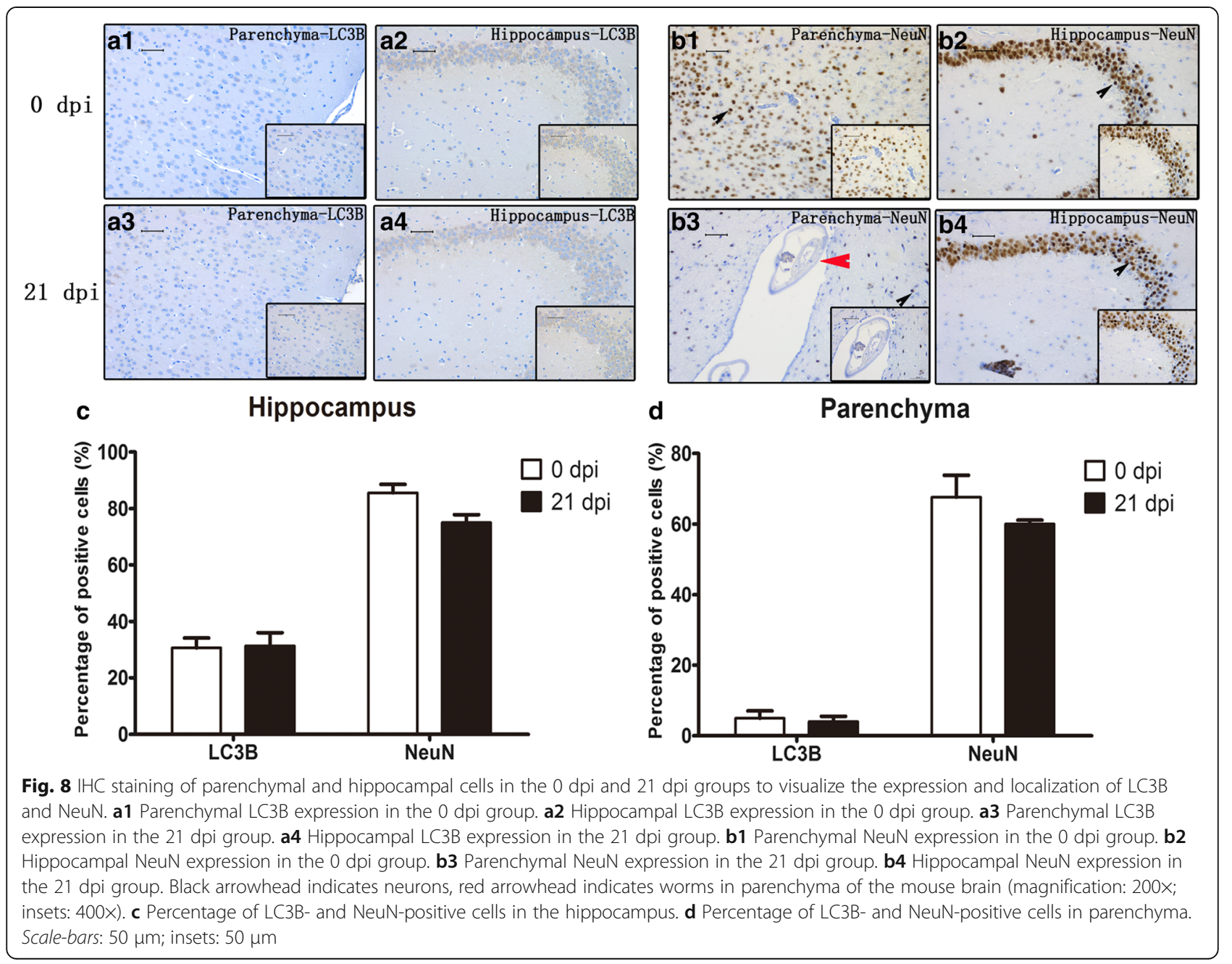


accumulation of LC3B-II can be observed in the mice infected with the parasite $(P>0.05)$ (Fig. 4).

\section{Caspase-3 and RIP3 in parenchymal and hippocampal cells}

Caspase-3 and RIP3 expression in the parenchymal and hippocampal cells of the $0 \mathrm{dpi}$ and $21 \mathrm{dpi}$ groups were analysed by quantitative RT-PCR and western blot. A significant elevation in the RIP3 mRNA level after infection was observed, as it was 2- and 3-fold higher than those of normal mice in parenchymal $\left(t_{(4)}=4.826, P=\right.$ 0.017 ) and hippocampal cells $\left(t_{(4)}=3.624, P=0.0152\right)$, respectively. Furthermore, no obvious alterations of the caspase-3 mRNA level were observed $(P>0.05)$ (Fig. 5a). Western blot analysis showed a correspondingly significant elevation of RIP3 and pRIP3 expression in post-
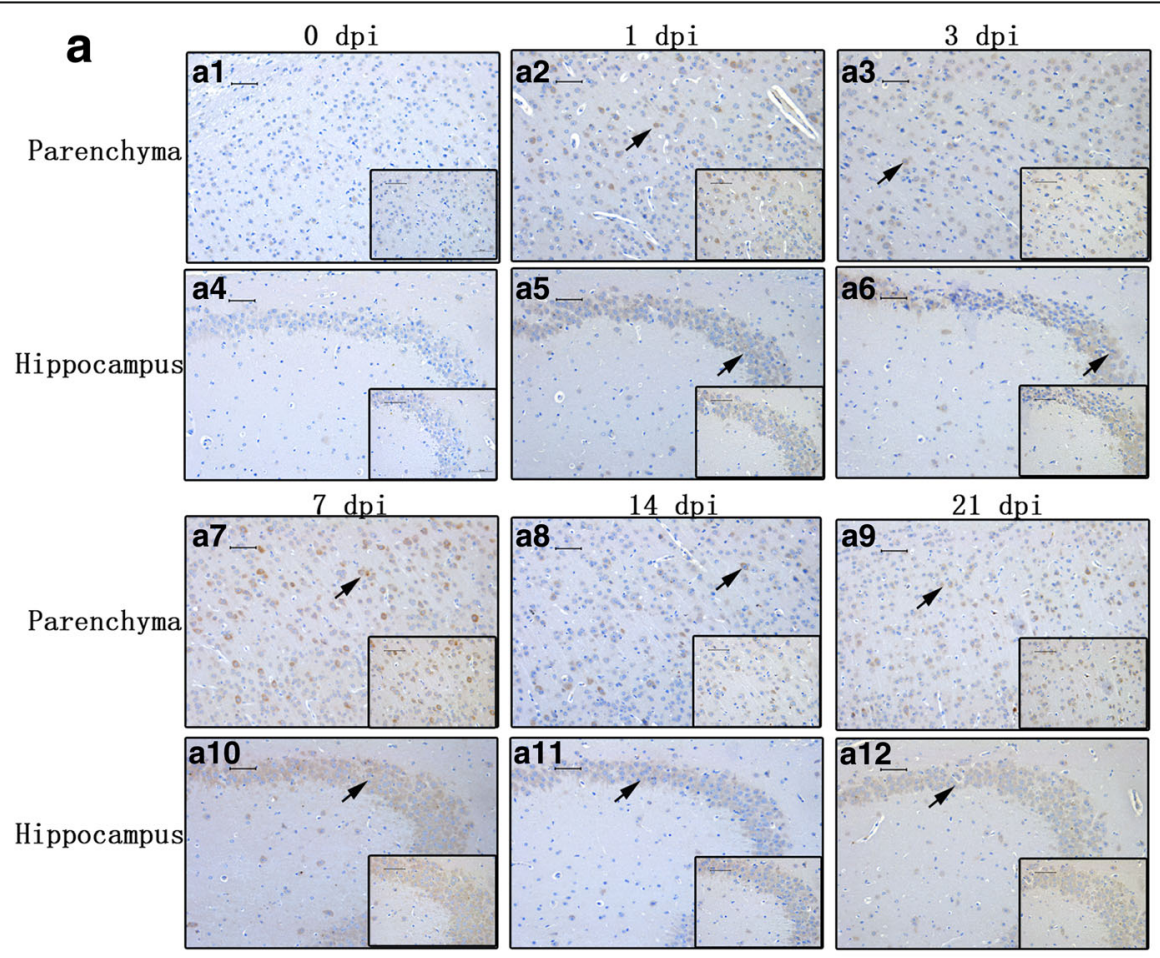

b

Cleaved caspase-3
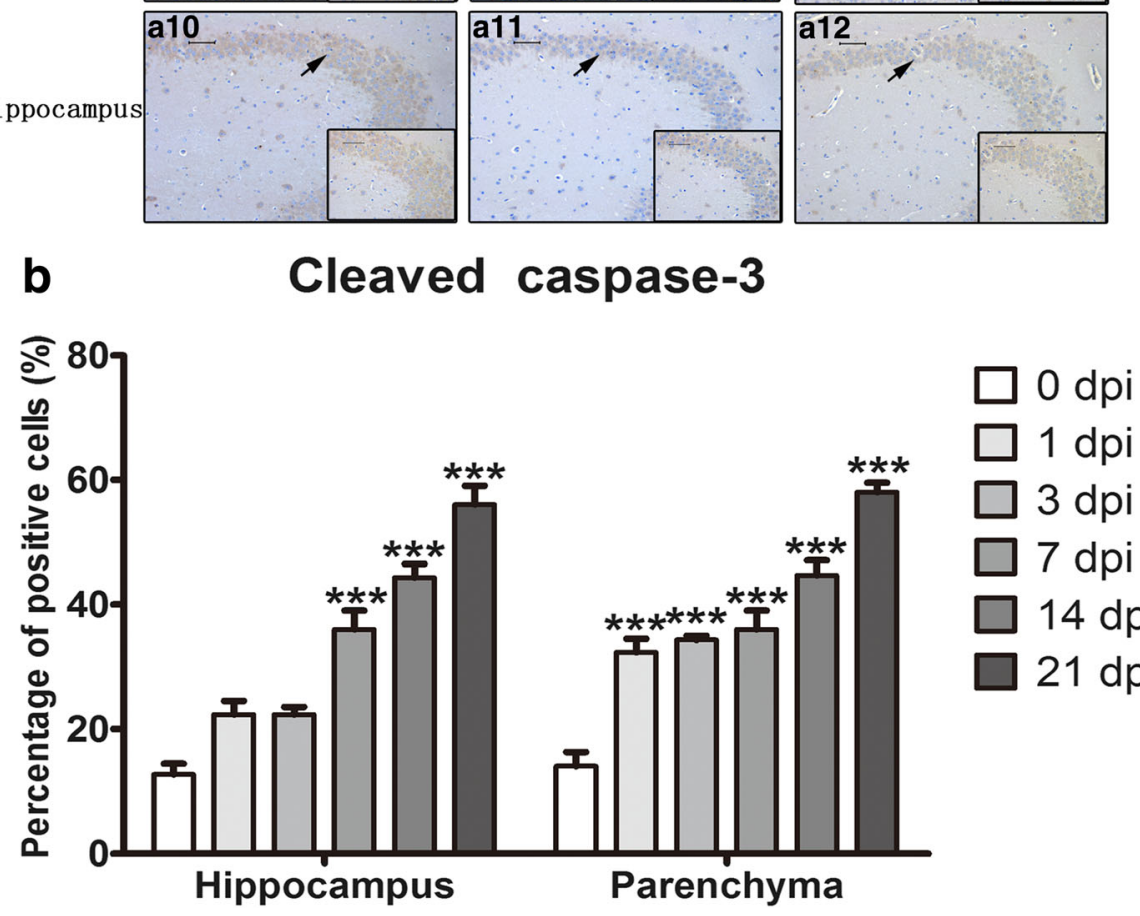

$\square 1 \mathrm{dpi}$

$\square 3 \mathrm{dpi}$

$\square 7 \mathrm{dpi}$

$\square 14 \mathrm{dpi}$

$\square 21 \mathrm{dpi}$

Fig. $9 \mathrm{HC}$ staining of brain parenchymal and hippocampal cells in the $0 \mathrm{dpi}$ group and at various post-infectious stages to compare the expression and localization of cleaved caspase-3. a1 Parenchyma, 0 d,pi . a2 Parenchyma, 1 dpi. a3 Parenchyma, 3 dpi. a4 Hippocampus, 0 dpi. a5 Hippocampus, 1 dpi. a6 Hippocampus, 3 dpi. a7 Parenchyma, 7 dpi. a8 Parenchyma, 14 dpi. a9 Parenchyma, 21 dpi. a10 Hippocampus, 7 dpi. a11 Hippocampus, 14 dpi. a12 Hippocampus, 21 dpi. Arrow indicates cleaved caspase-3-positive cells (magnification 400X). b Percentage of cleaved caspase-3-positive cells in hippocampal and parenchymal tissue. Scale-bars: $50 \mu \mathrm{m}$; insets: $50 \mu \mathrm{m}$ 
infectious parenchymal $\left(t_{(4)}=9.374, P=0.0007\right.$ and $t_{(4)}=$ 11.03, $P=0.0004$, respectively) and hippocampal cells $\left(t_{(4)}=9.139, P=0.0008\right.$ and $t_{(4)}=5.619, P=0.0049$, respectively). Similar conclusions were found regarding the cleaved caspase- 3 protein levels in parenchymal cells $\left(t_{(4)}=12.35, P=0.0002\right)$ and hippocampal cells $\left(t_{(4)}=7.3\right.$, $P=0.0019$ ) (Fig. 5b, c). All data indicated that $A$. cantonensis infection could result in apoptosis and necroptosis in mouse hippocampal and parenchymal cells.

\section{Apoptosis and necroptosis in infected mouse} parenchymal and hippocampal cells as detected by immunohistochemistry (IHC)

Expression and localization of caspase-3, cleaved caspase-3, caspase-6, RIP3, LC3B and NeuN were detected in the $0 \mathrm{dpi}$ and $21 \mathrm{dpi}$ groups by IHC. As shown in Figs. 6, 7, 8, cleaved caspase-3- and RIP3-positive cells were significantly increased in both parenchymal and hippocampal cells of the 21 dpi group. For cleaved

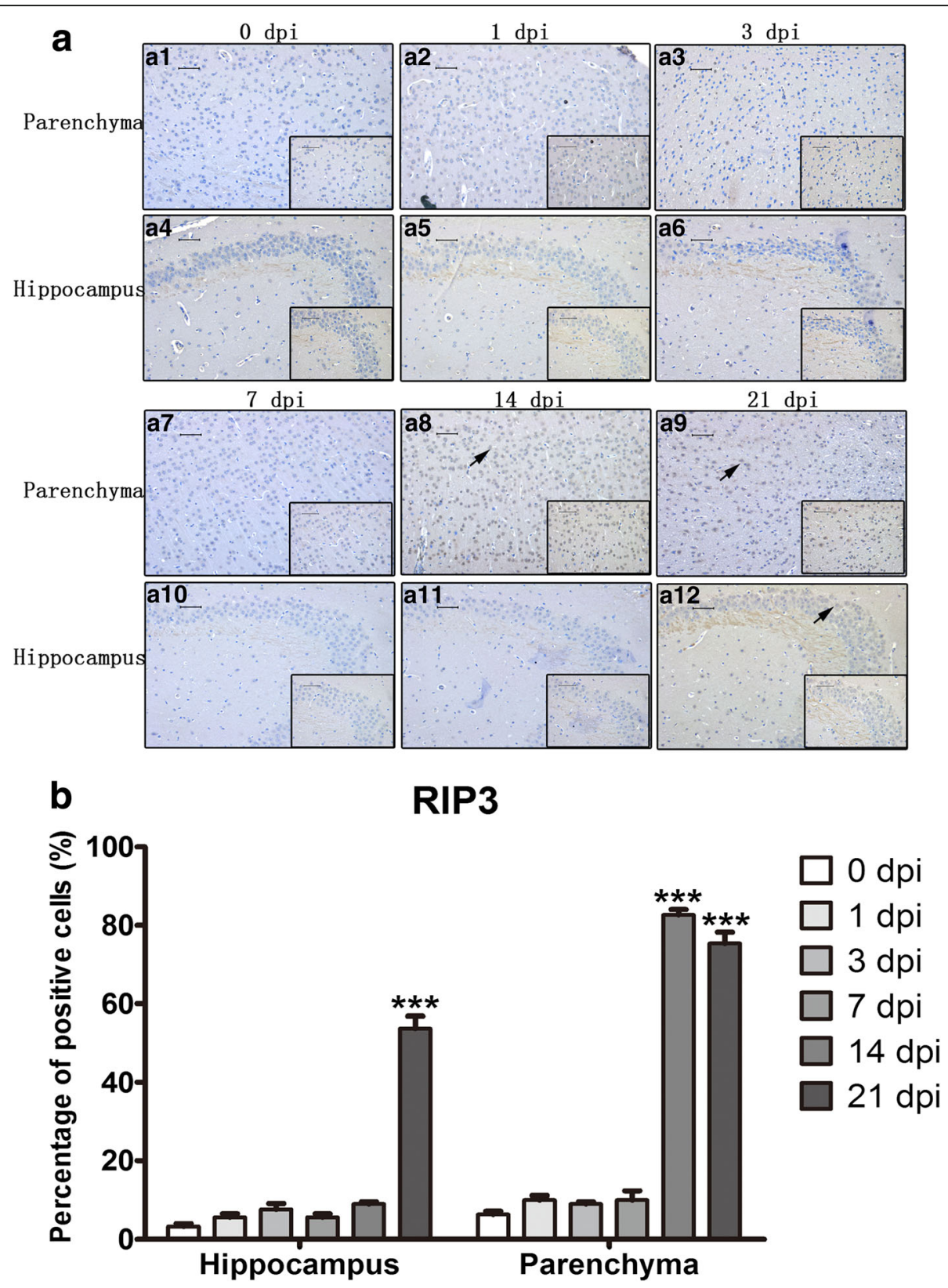

Fig. $10 \mathrm{HC}$ staining of brain parenchymal and hippocampal cells in the 0 dpi group and at various post-infectious stages to compare the expression and localization of RIP3. a1 Parenchyma, 0 dpi. a2 Parenchyma, 1 dpi. a3 Parenchyma, 3 dpi. a4 0 dpi hippocampus. a5 Hippocampus, 1 dpi. a6 Hippocampus, 3 dpi. a7 Parenchyma, 7 dpi. a8 Parenchyma,14 dpi. a9 Parenchyma, 21 dpi. a10 Hippocampus, 7 dpi. a11 Hippocampus, 14 dpi. a10 Hippocampus, 21 dpi. Arrow indicates RIP3-positive cells (magnification 200x; insets: 400x). b Percentage of RIP3-positive cells in hippocampal and parenchymal cells. Scale-bars: $50 \mu \mathrm{m}$; insets: $50 \mu \mathrm{m}$ 
caspase-3, the percentage of positive cells increased from $12.67 \pm 3.06 \%$ to $51 \pm 3.61 \%$ and $14 \pm 4 \%$ to $55.33 \pm 5.03 \%$ in the hippocampus and parenchyma, respectively. The number of RIP3-positive cells increased from $5.67 \pm 1.53 \%$ to $54.33 \pm 4.04 \%$ and $9.67 \pm 2.08 \%$ to $88.33 \pm 3.06 \%$ in the hippocampus and parenchyma, respectively. A mild elevation in the number of caspase- 6 -positive cells from $2 \pm 1 \%$ to $23 \pm 4.36 \%$ was observed in infected hippocampi, and no substantial changes were observed in the number of caspase-3positive cells. Neither normal nor infected mouse brains exhibited LC3B-positive cells, implying that $A$. cantonensis infection does not lead to autophagy. Different infectious stages were then measured by similar procedures. The number of cleaved caspase-3-positive cells gradually multiplied from $1 \mathrm{dpi}$ to $21 \mathrm{dpi}$ and peaked at $58 \pm 2.65 \%$ in parenchymal cells and $56 \pm$ $5.29 \%$ in hippocampal cells at 21 dpi (Figs. 9 and 10). Parenchymal RIP3-positive cells peaked at 14 dpi at $82.67 \pm 2.31 \%$, while hippocampal RIP3-positive cells peaked at $21 \mathrm{dpi}$ at $53.67 \pm 5.51 \%$ (Figs. 9 and 10). The IHC results further proved that post-infectious apoptosis and necroptosis occur in mouse hippocampal and parenchymal cells.

\section{Detection of cell death by flow cytometry}

Distinction between early-apoptotic cells and lateapoptotic/necrotic cells was detected by flow cytometry using the Annexin V PE-Cyanine7 and FVD eFluor 780 double-label staining technique. Proportions of lateapoptotic or necrotic parenchymal cells (Annexin V PECyanine7+/FVD eFluor 780+) in the $14 \mathrm{dpi}(48.9 \pm 2.3 \%)$ and $21 \mathrm{dpi}(22.25 \pm 11.38 \%)$ groups were significantly increased compared with those in the 0 dpi $(2.81 \pm 1.27 \%)$ and $7 \mathrm{dpi}(2.79 \pm 1.88 \%)$ groups (Fig. 11). Notably, the late-apoptotic or necrotic cell counts peaked at $14 \mathrm{dpi}$ $\left(F_{(3,8)}=66.33, P<0.0001\right)$, followed by a slight decline at 21 dpi in parenchymal cells. The latter still showed statistically significant distinction between the $0 \mathrm{dpi} / 7 \mathrm{dpi}$ $\left(F_{(3,8)}=66.33, P=0.01\right)$ and 14 dpi groups $\left(F_{(3,8)}=66.33\right.$, $P=0.002)$ compared with $21 \mathrm{dpi}$. Similarly, the proportions of late-apoptotic or necrotic hippocampal cells in the $14 \mathrm{dpi}(3.58 \pm 1.58 \%)$ and $21 \mathrm{dpi}(25.05 \pm 0.07 \%)$ groups were also significantly increased compared with

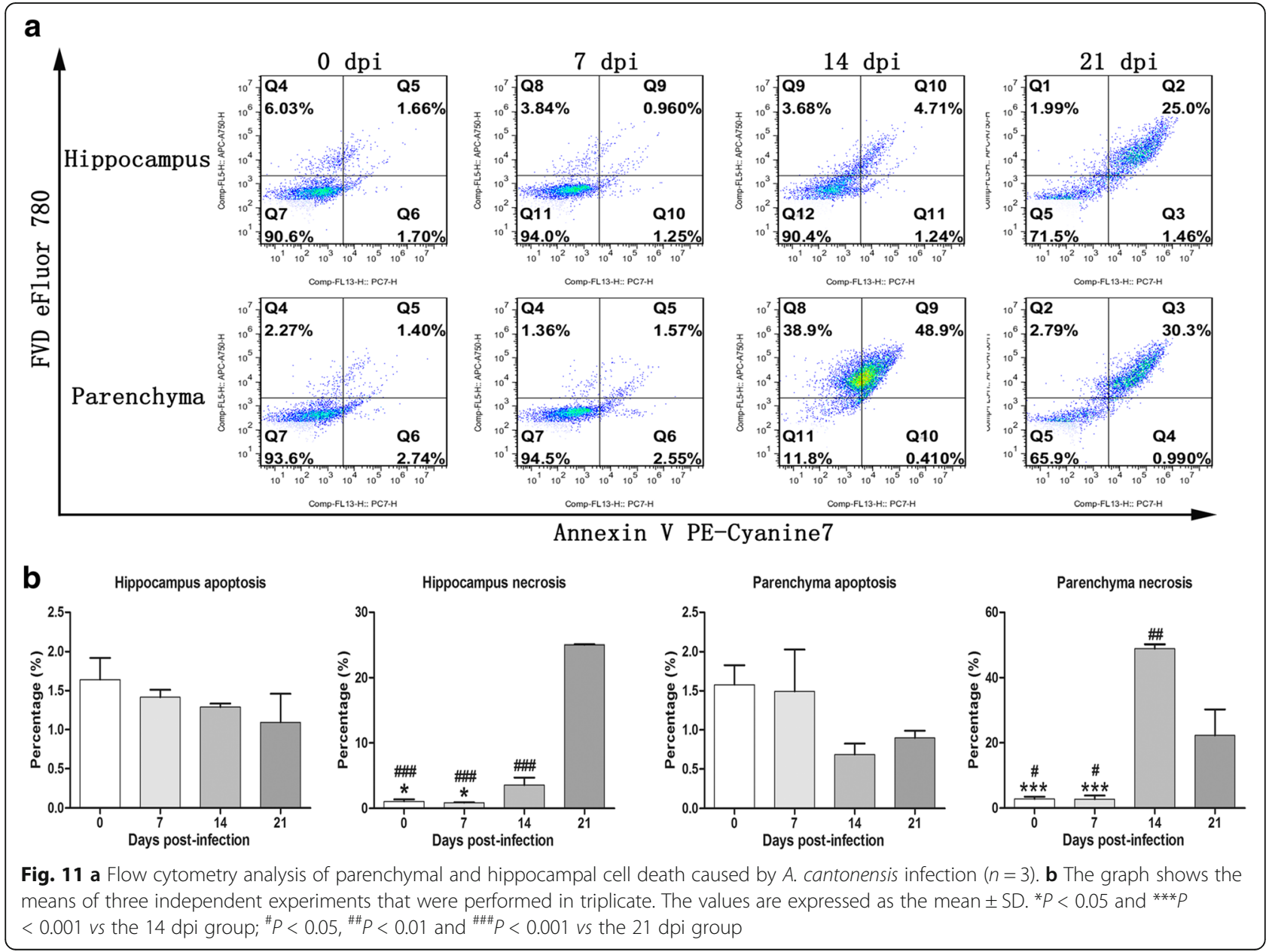


those in the 0 dpi $(1.09 \pm 0.49 \%)\left(F_{(3,8)}=590.3, P=0.032\right.$ and $F_{(3,8)}=590.3, P<0.0001$, respectively) and $7 \mathrm{dpi}(0.90 \pm$ $0.06 \%)$ group $\left(F_{(3,8)}=590.3, P=0.023\right.$ and $F_{(3,8)}=590.3, P<$ 0.0001 , respectively). The late-apoptotic and necrotic cell counts in hippocampal cells peaked at $21 \mathrm{dpi}$, with a statistically significant difference from those of the 14 dpi group $\left(F_{(3,8)}=590.3, P<0.0001\right)$. Furthermore, no significant distinctions in early-apoptotic cell counts (Annexin V PECyanine7+/FVD eFluor 780-) were found in any of the groups. The flow cytometry results revealed that apoptosis and necroptosis occur in hippocampal and parenchymal cells during $A$. cantonensis infection. The apoptotic and necrotic cell categories were further evaluated using different surface biomarkers (CD45 and CD11b for microglia, NeuN for neurons, GFAP for astrocytes). As indicated in Figs. 12 and 13, as the infection time extended, distinct elevations in the proportions of parenchymal and hippocampal astrocytes, neurons and microglia undergoing late

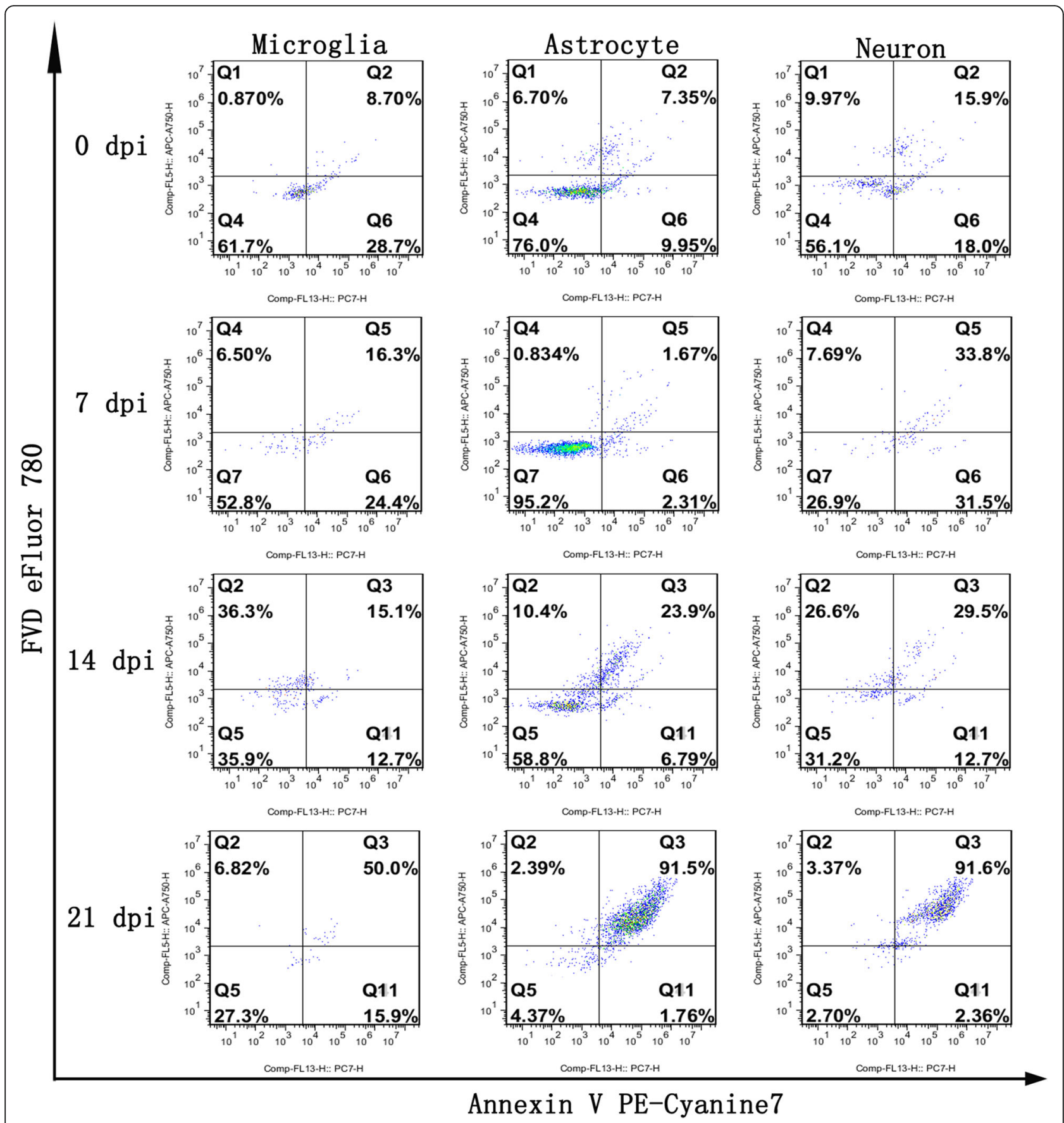

Fig. 12 Effect of $A$. cantonensis infection on mouse hippocampal cell death as analysed by flow cytometry 
apoptosis or necroptosis were observed, and almost $90 \%$ of the astrocytes and neurons had underwent apoptosis and necroptosis at $21 \mathrm{dpi}$.

Morphological changes in mouse brains infected with $A$. cantonensis as observed by TEM

Compared with the normal morphology and ultrastructure of cells in the 0 dpi group, the astrocytes (Figs. 14, 15f), microglia (Figs. 14g, 15k), oligodendrocytes (Fig. 15g) and neurons (Fig. 15h) of the $21 \mathrm{dpi}$ group showed apparent swelling, rupture and loss of nuclear membrane integrity and visible swollen organelles (Fig. 15i), indicating that these cells underwent necrosis. Neuronal pyknosis and shrinkage (Figs. 14h, 15m) revealed that the neurons may have undergone apoptosis. Characteristics of apoptotic cells, such as patchy nuclear

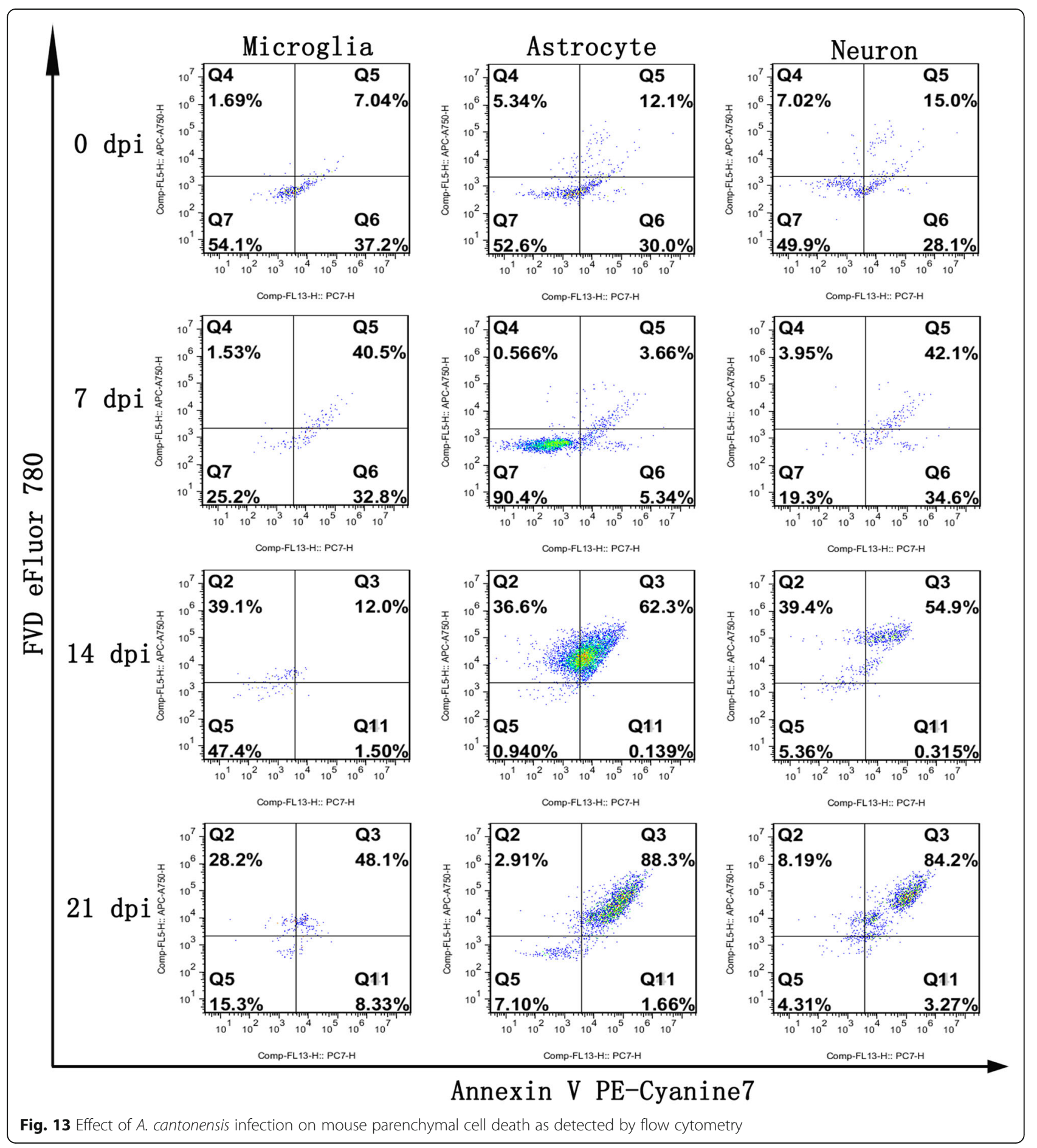




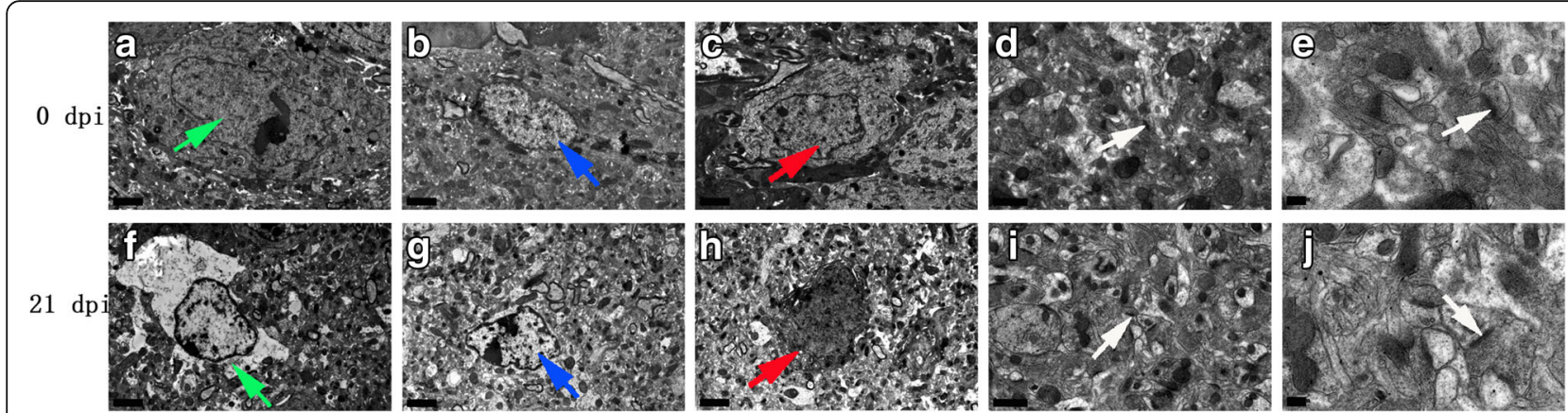

Fig. 14 Representative transmission electron micrographs of mouse hippocampal cells in the 0 dpi (a-e) and 21 dpi (f-j) groups. The green, blue, red and white arrows indicate astrocytes, microglia, neurons and intercellular synapses, respectively. a-c Normal appearance and ultrastructure. $\mathbf{f}$ Swollen and ruptured astrocytes. $\mathbf{g}$ Swollen microglia. $\mathbf{h}$ Shrunken neurons. No obvious synapse lesions were observed in $\mathbf{d}$, e, $\mathbf{i}$, $\mathbf{j}$ (magnification: a-c, f-h, 5800x; d, i, 13,500x; e, j, 37,000x). Scale-bars: a-c, f-h, $2 \mu \mathrm{m} ; \mathbf{d}, \mathbf{i}, 1 \mu \mathrm{m} ; \mathbf{e}, \mathbf{j}, 200 \mathrm{~nm}$

membranes, chromatin margination (Fig. 15l) and abnormally emerged smooth muscle cells (Fig. 15j), implied apoptosis and necroptosis of parenchymal and hippocampal cells. Hence, we concluded that significant morphological changes in hippocampal and parenchymal cells occur after $A$. cantonensis infection.

\section{Discussion}

Eosinophilic meningitis or eosinophilic meningoencephalitis in humans is commonly caused by Angiostrongylus cantonensis, a food-borne zoonotic parasite, in southern Asia and the Pacific and Caribbean islands [14, 15]. The clinical symptoms of angiostrongyliasis cantonensis are characterized by severe headache, neck stiffness, paraesthesias and cranial nerve palsy $[16,17]$. The neurological manifestations of neuroangiostrongyliasis include eosinophilic meningitis, encephalitis/encephalomyelitis, radiculitis and cranial nerve abnormalities, ataxia, tremors and paralysis, which have been observed in previous clinical reports [18-20] and in studies on infected experimental animal models $[11,21]$. These characteristics coincide with our results that infected mice exhibited extensive brain injury and neurological disorder, as detected by the Morris water maze test (Fig. 1) and H\&E staining (Fig. 2). However, the pathogenesis of A. cantonensis neurological dysfunction remains poorly understood. The tracks and microcavities caused by the migration of larvae in the brains of infected animals, as described in previous studies [21], cannot explain all the clinical neurological injuries in the hosts [20] or the

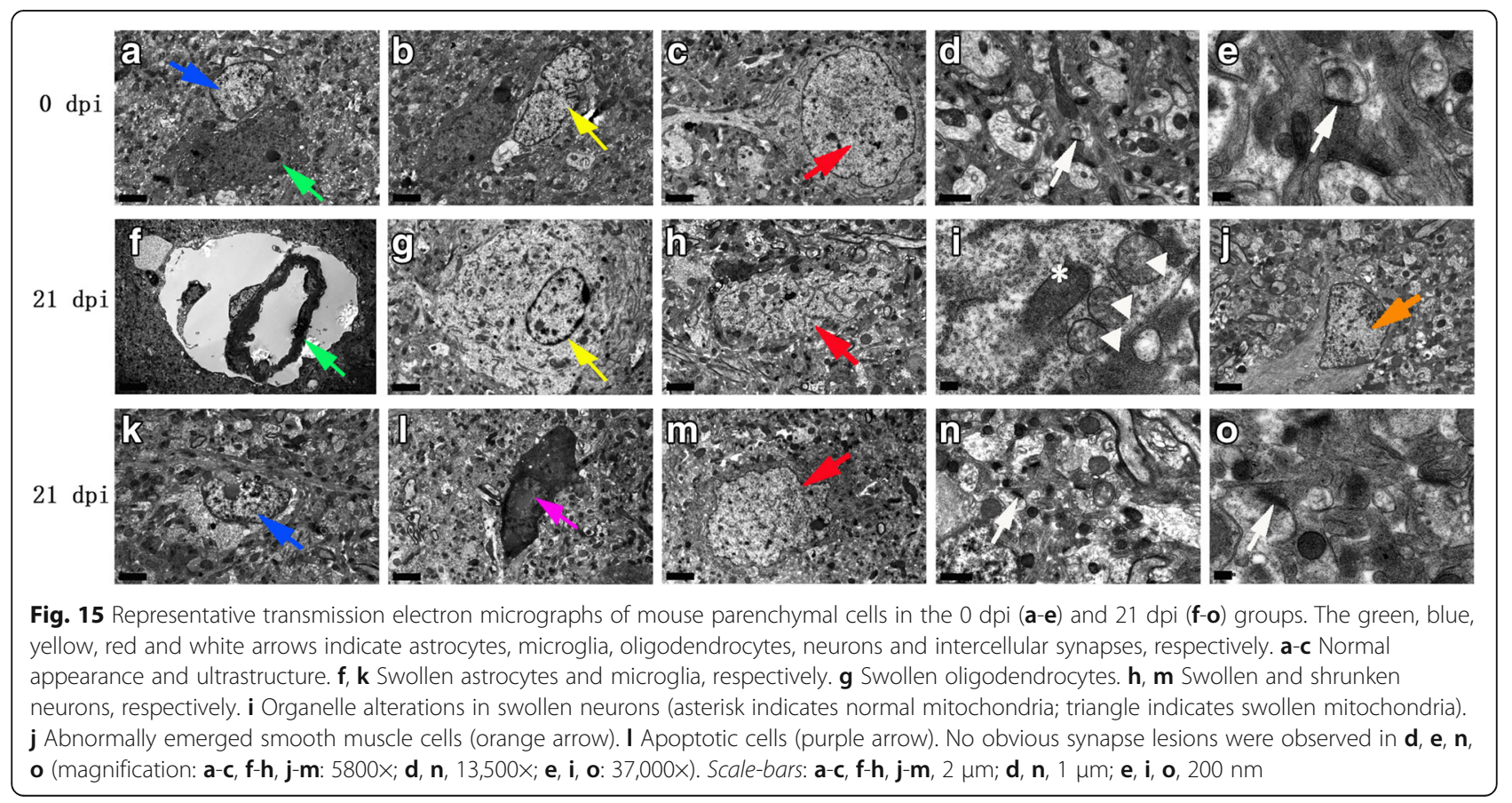


distinct outcomes between permissive and nonpermissive hosts after $A$. cantonensis infection since the same physical destruction of neural tissue caused by the migration of larvae can be seen within both of their brains [11]. Interestingly, our previous [22] and the current findings indicate the obvious apoptosis and necroptosis of parenchymal and hippocampal astrocytes, neurons and microglia of mice infected with $A$. cantonensis (Figs. 3-10), which might provide new insights into the pathogenesis of neuroangiostrongyliasis.

The cell is the basic structural and functional unit of life. Cell death, as a natural process of life, plays an important role in the development and homeostatic balance of multicellular organisms [23-25]. According to morphology and molecular mechanisms, cell death is mainly divided into three categories: apoptosis, autophagy, and necroptosis (or necrotic cell death) [26]. Apoptosis is an automatic and programmed process regulated by signalling pathways, including the death receptor signalling, mitochondria-mediated and endoplasmic reticulum stress pathways $[27,28]$. All the pathways ultimately activate caspases to complete apoptosis. Caspase-3, -4, and -6 are important members of the caspase family [29], as their function in orchestrating apoptosis has been widely confirmed [30]. In this study, we discovered that compared with those of uninfected mice, the caspase- 4 and -6 mRNA levels and cleaved caspase3, -4, and -6 expression levels of $A$. cantonensis-infected mice were elevated. As shown in Figs. 3 and 4, A. cantonensis infection could cause the apoptosis of mouse brain cells. Furthermore, qPCR, western blot, immunohistochemistry, flow cytometry and TEM analysis further proved that apoptosis mainly occurs in parenchymal and hippocampal astrocytes, neurons and microglia during A. cantonensis infection (Figs. 5-15). Although previous studies showed an elevation in the number of apoptotic leukocytes in post-infective parenchyma and subarachnoid space and the induction of apoptosis in endothelial cells and astrocytes after the addition of larvae extracts [31, 32], we observed for the first time in this study that A. cantonensis infection caused significant apoptosis amongst parenchymal and hippocampal astrocytes, neurons and microglia, which could partially account for the severe neural damage observed (Fig. 1). In addition, we first confirmed that the levels of RIP3 and pRIP3 increased as the infection time extended (Figs. 3, 4). RIP3 is the key to apoptosis and necroptosis and a specific marker for necroptosis [33]. Thus, the increased RIP3 and pRIP3 levels indicated that $A$. cantonensis infection could induce the necroptosis of astrocytes, neurons and microglia (Figs. 5-15). Necroptosis is a recently recognized mechanism of programmed cell death that, unlike apoptosis, shows necrotic morphological changes with a patterned regulatory mechanism [34, 35]. Necroptosis can be induced by TNF- $\alpha$, the activator of programmed cell death [36-38], and is mediated by its unique RIP3dependent signalling pathway. In most cases, apoptosis and necroptosis co-exist, and a main difference between them is that necroptosis is accompanied by inflammation [39], causing inflammatory diseases, such as neurodegenerative disorders, haemorrhage-induced brain damage, Crohn's disease, multiple sclerosis and certain viral infections [40]. Our study on A. cantonensis infection-induced brain apoptosis and necroptosis is not only consistent with our previous work in that the level of TNF- $\alpha$, a trigger of apoptosis and necroptosis that is increased in the brains of mice infected with $A$. cantonensis [41], can be directly induced by the cystatin from $A$. cantonensis (unpublished data), but also further explains the pathogenesis of severe neural dysfunction accompanied with extensive eosinophilic CNS inflammation during $A$. cantonensis infection.

As the macrophages of the brain, microglia play both protective and toxic (damaging) roles in non-infectious pathological states, such as brain damage or neurodegenerative disorders $[42,43]$. As the only immune cells in cerebral parenchyma, microglia are considered the first-line barrier protection for the CNS against pathogens (bacteria, viruses, parasites, etc.) [44-46]. Astrocytes are the most widely distributed cells in the mammalian brain and the largest population among glial cells [47]. Thus, astrocytes play significant roles in survival functionality, neuronal development and information transmission, neuronal maturation and synapse formation, CNS metabolism, and damaged blood-brain barrier repair and reconstruction [48, 49]. Neurons are the basic structural and functional units of the nervous system, and the key to neural function is the synaptic signalling process, which is partly electrical and partly chemical [50]. The essential function of neurons is to exchange messages through information input, integration, conduction and output. Thus, neurons are crucial to the sensation, learning, memory, cognition and movement of organisms [51, 52]. The apoptosis or necroptosis of microglia, astrocytes or neurons can lead to severe neural dysfunction (epilepsy, Alzheimer's disease, cerebrovascular disease, encephalitis, meningitis, etc.), or even death [53, 54]. Apoptosis and necroptosis occurred in microglia, astrocytes or neurons after A. cantonensis infection, indicating that neurotrophic agents and inhibitors of apoptosis and necroptosis could be effective in combination with anti-parasitic drugs (albendazole) and steroidal anti-inflammatory drugs (dexamethasone).

\section{Conclusions}

In summary, this study is the first to demonstrate that A. cantonensis infection can significantly induce the apoptosis and necroptosis of astrocytes, neurons and 
microglia in host brain parenchymal and hippocampal tissues. This not only enriches our understanding of $A$. cantonensis pathogenesis but also provides a clue to novel potential therapeutic strategies against angiostrongyliasis cantonensis.

\section{Abbreviations}

dpi: Days post-infection; HE: Hematoxylin and eosin;

IHC: Immunohistochemical; L1: First-stage larvae; L3: Third-stage larvae; RT-

PCR: Real-time polymerase chain reaction; TEM: Transmission electron microscopy

\section{Acknowledgements}

We sincerely appreciate that Dr Zeng xin and Mr. Lin Datao provided the parasites used in the present study and we thank Mrs. Guan Yuanjun and Dr Li Xiaobo for providing help with microscopy, flow cytometry and expert technical assistance.

\section{Funding}

This work was supported by grants from the National Natural Science Foundation of China (grant nos. 81371836 and 81572023), Guangdong Natural Science Foundation (grant no. 2014A030313134), Science and Technology Planning Project of Guangdong Province (grant no. 2016A050502008), the National Key Research and Development Program of China (grant nos. 2016YFC1202003, 2016YFC1202005 and 2016YFC1200500) the Project of Basic Platform of National Science and Technology Resources of the Ministry of Sciences and Technology of China (grant no. TDRC-201722), Science and Technology Planning Project of Guangzhou (grant no. 201607010029), the 111 Project (grant no. B12003), the Undergraduates Innovation Training Program of Guangdong Province (grant nos. 201410558274 and 201601084) and Teaching Reform Project of Sun Yat-sen University (grant no. 2016012).

\section{Availability of data and materials}

The datasets used and/or analysed during the current study are available from the corresponding author upon reasonable request.

\section{Authors' contributions}

LZY and WZ conceived and designed the experiments and drafted the manuscript; ZMY participated in drafting the manuscript; ZMY, PT and XYY performed the experiments; HY, YL, HP and KO collected and analyzed the data; WYQ, PD, ZHL, DW and WZD participated in study design, technological guidance and coordination. All authors read and approved the final manuscript.

\section{Ethics approval}

All animal procedures in this study were reviewed and approved by the Institutional Animal Care and Use Committee of Sun Yat-sen University and were operated in accordance with the regulations of the Guide for the Care and Use of Experimental Animals of the National Institutes of Health.

\section{Consent for publication}

Not applicable.

\section{Competing interests}

The authors declare that they have no competing interests.

\section{Publisher's Note}

Springer Nature remains neutral with regard to jurisdictional claims in published maps and institutional affiliations.

\section{Author details}

${ }^{1}$ Fifth Affiliated Hospital, Zhongshan School of Medicine, Sun Yat-sen University, Guangzhou 510080, China. ${ }^{2}$ Key Laboratory of Tropical Disease Control (Sun Yat-sen University), Ministry of Education, Guangzhou 510080, China. ${ }^{3}$ Provincial Engineering Technology Research Center for Biological Vector Control, Guangzhou 510080, China. ${ }^{4}$ Faculty of Tropical Medicine, Mahidol University, Bangkok 10400, Thailand. ${ }^{5}$ College of Bioscience \& Biotechnology, Hunan Agriculture University, Changsha 410128, China.
Received: 14 August 2017 Accepted: 3 December 2017

Published online: 19 December 2017

\section{References}

1. Wang QP, Lai DH, Zhu XQ, Chen XG, Lun ZR. Human angiostrongyliasis. Lancet Infect Dis. 2008:8:621-30.

2. Song L, Wang X, Yang Z, LV Z, Wu Z. Angiostrongylus cantonensis In the vector snails Pomacea canaliculata and Achatina fulica in China: a metaanalysis. Parasitol Res. 2016;115:913-23.

3. Martins YC, Tanowitz HB, Kazacos KR. Central nervous system manifestations of Angiostrongylus cantonensis infection. Acta Trop. 2015;141:46-53.

4. Pittella JE. Pathology of CNS parasitic infections. Handb Clin Neurol. 2013; 114:65-88.

5. Stanley SL Jr. Amoebiasis. Lancet. 2003;361:1025-34.

6. Milner DA Jr. Rethinking cerebral malaria pathology. Curr Opin Infect Dis. 2010;23:456-63.

7. Zepeda N, Solano S, Copitin N, Chávez JL, Fernández AM, García F, et al. Apoptosis of mouse hippocampal cells induced by Taenia crassiceps metacestode factor. J Helminthol. 2017;91:215-21.

8. Sikasunge CS, Phiri IK, Johansen MV, Willingham AL 3rd, Leifsson PS. Hostcell apoptosis in Taenia solium-induced brain granulomas in naturally infected pigs. Parasitology. 2008;135:1237-42.

9. Jellinger KA, Setinek U, Drlicek M, Böhm G, Steurer A, Lintner F. Neuropathology and general autopsy findings in AIDS during the last 15 years. Acta Neuropathol. 2000;100:213-20.

10. Scrimgeour EM, Gajdusek DC. Involvement of the central nervous system in Schistosoma mansoni and S. haematobium infection. A review. Brain. 1985; 108:1023-38.

11. Li S, Yang F, Ji P, Zeng X, Wu X, Wei J, et al. Eosinophil chemotactic chemokine profilings of the brain from permissive and non-permissive hosts infected with Angiostrongylus cantonenis. Parasitol Res. 2014;113:51725.

12. Ji L, Yiyue $X$, Xujin $H$, Minghui $Z$, Mengying $Z$, Yue $H$, et al. Study on the tolerance and adaptation of rats to Angiostrongylus cantonensis infection. Parasitol Res. 2017:116:1937-45.

13. Ji P, Hu H, Yang X, Wei X, Zhu C, Liu J, et al. AcCystatin, an immunoregulatory molecule from Angiostrongylus cantonensis, ameliorates the asthmatic response in an aluminium hydroxide/ovalbumin-induced rat model of asthma. Parasitol Res. 2015;114:613-24.

14. McBride A, Chau TTH, Hong NTT, Mai NTH, Anh NT, Thanh TT, et al. Angiostrongylus cantonensis is an important cause of eosinophilic meningitis in southern Vietnam. Clin Infect Dis. 2017;64:1784-7.

15. Guerino LR, Pecora IL, Miranda MS, Aguiar-Silva C, Carvalho OD, Caldeira RL, et al. Prevalence and distribution of Angiostrongylus cantonensis (Nematoda, Angiostrongylidae) in Achatina fulica (Mollusca, Gastropoda) in Baixada Santista, São Paulo, Brazil. Rev Soc Bras Med Trop. 2017;50:92-8.

16. Lv S, Zhou XN, Andrews JR. Eosinophilic meningitis caused by Angiostrongylus cantonensis. ACS Chem Neurosci. 2017; https://doi.org/10, 1021/acschemneuro.7b00233.

17. Eamsobhana P. Eosinophilic meningitis caused by Angiostrongylus cantonensis - a neglected disease with escalating importance. Trop Biomed. 2014;31:569-78.

18. Sawanyawisuth K, Takahashi K, Hoshuyama T, Sawanyawisuth K, Senthong V Limpawattana $\mathrm{P}$, et al. Clinical factors predictive of encephalitis caused by Angiostrongylus cantonensis. Am J Trop Med Hyg. 2009;81:698-701.

19. Al Hammoud R, Nayes SL, Murphy JR, Heresi GP, Butler IJ, Pérez N. Angiostrongylus cantonensis meningitis and myelitis, Texas, USA. Emerg Infect Dis. 2017;23:1037-8.

20. Barratt J, Chan D, Sandaradura I, Malik R, Spielman D, Lee R, et al. Angiostrongylus cantonensis: a review of its distribution, molecular biology and clinical significance as a human pathogen. Parasitology. 2016;143:1087-118.

21. OuYang L, Wei J, Wu Z, Zeng X, Li Y, Jia Y, et al. Differences of larval development and pathological changes in permissive and nonpermissive rodent hosts for Angiostrongylus cantonensis infection. Parasitol Res. 2012; 111:1547-57.

22. Luo S, OuYang L, Wei J, Wu F, Wu Z, Lei W, et al. Neuronal apoptosis: pathological basis of behavioral dysfunctions induced by Angiostrongylus cantonensis in rodents model. Korean J Parasitol. 2017;55(3):267-78.

23. Kolb JP, Oguin TH 3rd, Oberst A, Martinez J. Programmed cell death and inflammation: winter is coming. Trends Immunol 2017; doi:https://doi.org/ 10.1016/j.it.2017.06.009. 
24. Jorgensen I, Rayamajhi M, Miao EA. Programmed cell death as a defence against infection. Nat Rev Immunol. 2017;17:151-64.

25. Green DR. The cell's dilemma, or the story of cell death: an entertainment in three acts. FEBS J. 2016;283:2568-76.

26. Vanden Berghe T, Kaiser WJ, Bertrand MJ, Vandenabeele P. Molecular crosstalk between apoptosis, necroptosis, and survival signaling. Mol Cell Oncol. 2015;2:e975093.

27. Peña-Blanco A, García-Sáez AJ. Bax, Bak and beyond: mitochondrial performance in apoptosis. FEBS J. 2017; https://doi.org/10.1111/febs.14186.

28. Fulda S. Apoptosis pathways and neuroblastoma therapy. Curr Pharm Des. 2009;15:430-5

29. Wu H, Che X, Zheng Q, Wu A, Pan K, Shao A, et al. Caspases: a molecular switch node in the crosstalk between autophagy and apoptosis. Int J Biol Sci. 2014;10:1072-83.

30. Kuranaga E. Beyond apoptosis: caspase regulatory mechanisms and functions in vivo. Genes Cells. 2012;17:83-97.

31. Song MS, Posse de Chaves El. Inhibition of rat sympathetic neuron apoptosis by ceramide. Role of p75NTR in ceramide generation. Neuropharmacology. 2003:45:1130-50.

32. Hu X, Li JH, Lan L, FF W, Zhang EP, Song ZM, et al. Vitro study of the effects of Angiostrongylus cantonensis larvae extracts on apoptosis and dysfunction in the blood-brain barrier (BBB). PLoS One. 2012;7:e32161.

33. Berger SB, Bertin J, Gough PJ. LiFe after death: RIP1 and RIP3 move beyond necroptosis. Cell Death Discov. 2016;2:16056.

34. Dunai Z, Bauer PI, Mihalik R. Necroptosis: biochemical, physiological and pathological aspects. Pathol Oncol Res. 2011;17:791-800.

35. Weinlich R, Oberst A, Beere HM, Green DR. Necroptosis in development, inflammation and disease. Nat Rev Mol Cell Biol. 2017:18:127-36.

36. Chen Y, Zou Z, Wu Z, Zhao Z, Luo X, Xie C, et al. TNF-a-induced programmed cell death in the pathogenesis of acquired aplastic anemia. Expert Rev Hematol. 2015;8:515-26

37. Vanlangenakker $N$, Vanden Berghe $T$, Vandenabeele $P$. Many stimuli pull the necrotic trigger, an overview. Cell Death Differ. 2012;19:75-86.

38. Sosna J, Voigt S, Mathieu S, Lange A, Thon L, Davarnia P, et al. TNF-induced necroptosis and PARP-1-mediated necrosis represent distinct routes to programmed necrotic cell death. Cell Mol Life Sci. 2014;71:331-48.

39. Newton K, Manning G. Necroptosis and inflammation. Annu Rev Biochem. 2016:85:743-63.

40. Golstein P, Kroemer G. Cell death by necrosis: towards a molecular definition. Trends Biochem Sci. 2007;32:37-43.

41. Yu L, Wu X, Wei J, Liao Q, Xu L, Luo S, et al. Preliminary expression profile of cytokines in brain tissue of BALB/C mice with Angiostrongylus cantonensis infection. Parasit Vectors. 2015:8:328.

42. Ramirez Al, de Hoz R, Salobrar-Garcia E, Salazar JJ, Rojas B, Ajoy D, et al. The role of microglia in retinal neurodegeneration: Alzheimer's disease, Parkinson, and glaucoma. Front Aging Neurosci. 2017;9:214.

43. Han J, Harris RA, Zhang XM. An updated assessment of microglia depletion: current concepts and future directions. Mol Brain. 2017;10:25.

44. Das Sarma J. Microglia-mediated neuroinflammation is an amplifier of virusinduced neuropathology. J Neuro-Oncol. 2014;20:122-36.

45. Erny $D$, Hrabě de Angelis $A L$, Prinz M. Communicating systems in the body: how microbiota and microglia cooperate. Immunology. 2017;150:7-15.

46. Rock RB, Gekker G, Hu S, Sheng WS, Cheeran M, Lokensgard JR, et al. Role of microglia in central nervous system infections. Clin Microbiol Rev. 2004;17:942-64.

47. Lundgaard I, Osório MJ, Kress BT, Sanggaard S, Nedergaard M. White matter astrocytes in health and disease. Neuroscience. 2014;276:161-73.

48. Dossi E, Vasile F, Rouach N. Human astrocytes in the diseased brain. Brain Res Bull. 2017; https://doi.org/10.1016/j.brainresbull.2017.02.001.

49. Ben Haim L, Rowitch DH. Functional diversity of astrocytes in neural circuit regulation. Nat Rev Neurosci. 2017;18:31-41.

50. Rizzolatti G, Craighero L. The mirror-neuron system. Annu Rev Neurosci. 2004:27:169-92.

51. Yang N, Ng YH, Pang ZP, Südhof TC, Wernig M. Induced neuronal cells: how to make and define a neuron. Cell Stem Cell. 2011:9:517-25.

52. Louis ED. From neurons to neuron neighborhoods: the rewiring of the cerebellar cortex in essential tremor. Cerebellum. 2014;13:501-12.

53. Goldstein DS. Biomarkers, mechanisms, and potential prevention of catecholamine neuron loss in Parkinson disease. Adv Pharmacol. 2013;68: 235-72.

54. Finsterer J, Burgunder JM. Recent progress in the genetics of motor neuron disease. Eur J Med Genet. 2014;57:103-12.

\section{Submit your next manuscript to BioMed Central and we will help you at every step:}

- We accept pre-submission inquiries

- Our selector tool helps you to find the most relevant journal

- We provide round the clock customer support

- Convenient online submission

- Thorough peer review

- Inclusion in PubMed and all major indexing services

- Maximum visibility for your research

Submit your manuscript at www.biomedcentral.com/submit
Biomed Central 